\title{
Conhecimento e uso da contracepção na adolescência: contribuições da assistência de enfermagem
}

\author{
Knowledge and use of contraception in adolescence: contributions of nursing care \\ Conocimiento y uso de la anticoncepción en la adolescencia: aportes del cuidado de enfermería
}

Recebido: 19/08/2021 | Revisado: 26/08/2021 | Aceito: 03/09/2021 | Publicado: 05/09/2021

Airton César Leite

ORCID: https://orcid.org/0000-0001-7184-8488

Centro Universitário Santo Agostinho, Brasil

E-mail: ainton.cesar2014@gmail.com

Mariana Pereira Barbosa Silva

ORCID: https://orcid.org/0000-0003-0852-8099

Universidade Estadual do Piauí, Brasil

E-mail: marianapbsilvaa@gmail.com

Juliana Torres Avelino

ORCID: https://orcid.org/0000-0002-8732-1856

Centro Universitário Santo Agostinho, Brasil

E-mail: juliana_avelinno@hotmail.com

Geovana Maria Rodrigues de Sousa

ORCID: https://orcid.org/0000-0001-6398-8560

Centro Universitário Santo Agostinho, Brasil

E-mail: geovanamaria08@hotmail.com

Maria Vitalina Alves de Sousa

ORCID: https://orcid.org/0000-0003-4448-2489

Centro Universitário INTA, Brasil

E-mail: enf.vitalinaalves@gmail.com

Maria Vitória Rodrigues Barbosa

ORCID: https://orcid.org/0000-0001-9751-3758

Centro Universitário Santo Agostinho, Brasil

E-mail: rodriguesvitoria411@gmail.com

Dayná Gomes Soares dos Santos

ORCID: https://orcid.org/0000-0001-7157-0949

Centro Universitário Santo Agostinho, Brasil E-mail: dayna.gomes64@gmail.com

Samuel Lopes dos Santos

ORCID: https://orcid.org/0000-0003-3375-9171 Universidade Federal do Piauí, Brasil

E-mail: samuellopes121314@gmail.com

Thatyani de Araújo Miura

ORCID: https://orcid.org/0000-0001-9777-6718

Centro Universitário Santo Agostinho, Brasil

E-mail: thatyanimiura902@gmail.com

Maria Clara de Carvalho Freire Fernandes

ORCID: https://orcid.org/0000-0002-4924-0457

Centro Universitário Santo Agostinho, Brasil

E-mail: clarafernandesthe@gmail.com

Shirley Cardoso Morais

ORCID: https://orcid.org/0000-0001-8920-7945

Centro Universitário Santo Agostinho, Brasil E-mail: shirleycmorais27@gmail.com

Cynthia Patrícia de Sousa Cardoso ORCID: https://orcid.org/0000-0002-6504-1394

Centro Universitário Santo Agostinho, Brasil E-mail: patriciacynthia89@gmail.com

Erica Williams de Moreira Lima ORCID: https://orcid.org/0000-0003-3957-5699

Centro Universitário Uninovafapi, Brasil

E-mail: williams-erica1992@outlook.com

Vanessa Lorrana Correia de Sousa ORCID: https://orcid.org/0000-0001-8159-6763 Associação de Ensino Superior do Piauí, Brasil

E-mail: enfervanessalorrana@gmail.com 


\author{
Maria Celita Vieira Pedreira \\ ORCID: https://orcid.org/0000-0001-6287-6532 \\ Centro Universitário Unifapi, Brasil \\ E-mail: mariacelitaaa@gmail.com \\ Aryanna Quadros Maniçoba \\ ORCID: https://orcid.org/0000-0003-0575-3485 \\ Centro Universitário Uninovafapi, Brasil \\ E-mail: aryannaquadros.61@gmail.com \\ Raimunda da Silva Sousa Neta \\ ORCID: https://orcid.org/0000-0001-5927-0046 \\ Centro Universitário Santo Agostinho, Brasil \\ E-mail: raynettasousa@gmail.com \\ Karla Cynthia dos Santos e Silva \\ ORCID: https://orcid.org/0000-0003-4080-0048 \\ Universidade Estadual da Paraíba, Brasil \\ E-mail: kcynthia7283@gmail.com \\ Shandallyane Ludce Pinheiro de Farias \\ ORCID: https://orcid.org/0000-0002-9180-6733 \\ Centro Universitário Santo Agostinho, Brasil \\ E-mail: ludcepinheiro@ hotmail.com \\ Bruna Karinnay da Silva Sousa \\ ORCID: https://orcid.org/0000-0002-2494-284X \\ Centro Universitário Santo Agostinho, Brasil \\ E-mail: karinnay@gmail.com \\ Layanne Cavalcante de Moura \\ ORCID: https://orcid.org/0000-0003-2781-1076 \\ Centro Universitário Unifacid, Brasil \\ E-mail: layannecavalcante@hotmail.com \\ Joelma Maria dos Santos da Silva Apolinário \\ ORCID: https://orcid.org/0000-0001-9521-9432 \\ Faculdade Maurício de Nassau, Brasil. \\ E-mail: jo.silva00@hotmail.com \\ Samara Atanielly Rocha \\ ORCID: https://orcid.org/0000-0002-5622-9280 \\ Faculdade de Saúde e Humanidades Ibituruna, Brasil \\ E-mail: samaraatanielly@ outlook.com
}

\title{
Resumo
}

Analisar as evidências científicas publicadas sobre o conhecimento e uso da contracepção na adolescência: contribuições da assistência de enfermagem. O presente estudo trata de uma revisão bibliográfica do método revisão integrativa da literatura, realizado nos meses entre março a agosto de 2021. A busca efetuou-se, através da Plataforma da Biblioteca Virtual em Saúde - BVS, utilizando as bases de dados LILACS, BDENF, por meio da SCIELO. Aderindo-se através dos descritores/palavras chaves: "Cuidados de Enfermagem", "Anticoncepcionais", "Adolescente", "Educação em Saúde", combinados com o operador booleano "AND”. O papel do enfermeiro como educador em saúde atuando em unidades básicas de saúde, entre outros espaços sociais, como a escola, devidamente capacitados para a função educativa, auxiliando o adolescente no processo de construção do conhecimento e sua utilização para o autocuidado. As ações de educação em saúde abordando temas como sexualidade, métodos contraceptivos e as IST's, HIV e AIDS são consideradas como ferramenta importante na promoção da saúde e prevenção de doenças. É necessário construir um conhecimento crítico dos adolescentes em relação a sua saúde, favorecendo a eles o empoderamento de cuidar de si próprio, os responsabilizando de manter sua saúde e se prevenir contra as IST's e uma gravidez indesejada. O conhecimento adequado sobre os diversos métodos contraceptivos disponíveis pelos jovens é de grande importância para que seja feita a melhor escolha, adequando-a as condições socioeconômicas, comportamento sexual, além de auxiliar o uso correto.

Palavras-chave: Cuidados de enfermagem; Anticoncepcionais; Adolescente; Educação em saúde.

\begin{abstract}
To analyze published scientific evidence on the knowledge and use of contraception in adolescence: contributions from nursing care. This study is a literature review of the integrative literature review method, carried out in the months between March and August 2021. The search was carried out through the Virtual Health Library Platform VHL, using the LILACS, BDENF databases, through SCIELO. Adhering through the descriptors/key words: "Nursing Care", "Contraceptional", “Adolescent", "Health Education", combined with the Boolean operator "AND”. The role of nurses as health educators working in basic health units, among other social spaces such as schools, properly trained for the educational function, helping adolescents in the process of knowledge construction and its use for self-care. health education actions addressing topics such as sexuality, contraceptive methods and STIs, HIV and AIDS are considered an important tool in health promotion and disease prevention. It is necessary to build critical knowledge of adolescents in relation to their health, favoring them with the empowerment of taking care of
\end{abstract}


themselves, making them responsible for maintaining their health and preventing STIs and unwanted pregnancy. Adequate knowledge about the various contraceptive methods available to young people is of great importance so that the best choice is made, adapting it to socioeconomic conditions, sexual behavior, in addition to assisting in the correct use.

Keywords: Nursing care; Contraceptives; Adolescent; Health education.

\section{Resumen}

Analizar la evidencia científica publicada sobre el conocimiento y uso de la anticoncepción en la adolescencia: aportes del cuidado de enfermería. El presente estudio es una revisión bibliográfica del método de revisión integradora de la literatura, realizada en los meses comprendidos entre marzo y agosto de 2021. La búsqueda se realizó a través de la Plataforma Biblioteca Virtual en Salud - BVS, utilizando las bases de datos LILACS, BDENF, a través de SCIELO. Adhiriéndose a los descriptores / palabras clave: "Atención de enfermería", “Anticoncepción", "Adolescente", "Educación para la salud", combinado con el operador booleano "Y". El rol de las enfermeras como educadoras en salud que laboran en las unidades básicas de salud, entre otros espacios sociales como las escuelas, debidamente capacitadas para la función educativa, ayudando a los adolescentes en el proceso de construcción del conocimiento y su uso para el autocuidado. Las acciones de educación para la salud que abordan temas como la sexualidad, los métodos anticonceptivos y las ITS, el VIH y el SIDA se consideran una herramienta importante en la promoción de la salud y la prevención de enfermedades. Es necesario construir un conocimiento crítico de las adolescentes en relación a su salud, favoreciéndolas con el empoderamiento de cuidarse a sí mismas, haciéndolas responsables de mantener su salud y prevenir las ITS y embarazos no deseados. El conocimiento adecuado de los distintos métodos anticonceptivos a disposición de los jóvenes es de gran importancia para que se haga la mejor elección, adecuándola a las condiciones socioeconómicas, comportamientos sexuales, además de ayudar en el correcto uso.

Palabras clave: Cuidado de enfermera; Anticonceptivos; Adolescente; Educación para la salud.

\section{Introdução}

A adolescência, é a fase que compreende entre 10 a 19 anos de idade, é um período permeado de alterações físicas e psíquicas e paralelamente a este processo pode dar-se início a vida sexual. Esta iniciação pode tornar o adolescente vulnerável a situações indesejadas, como a ocorrência de gravidez, contaminação por Infecções Sexualmente Transmissíveis (IST), entre outras, que repercutirão em seu futuro pessoal e profissional e/ou da qualidade de vida. Para prevenção destes riscos, vê-se a importância do uso de métodos contraceptivos como um direito que possibilita, cada vez mais, o ser humano ao exercício da sexualidade desvinculado da procriação. Nesse processo de construção da identidade da saída da infância e entrada na vida adulta, a transição do adolescente por vários contextos pode levar ao aparecimento de comportamentos de risco, como abuso de substâncias psicoativas, comportamento sexual de risco e violência (Rodrigues, \& Jardim, 2012).

A adolescência constitui-se de uma fase no processo evolutivo do indivíduo, marcada tanto pela idade cronológica como por alterações biológicas, psicossociais e socioculturais. É caracterizada pela transição da infância para idade adulta, com definição de fenômenos comuns como a maturação sexual e puberdade, bem como, pela vivência pessoal e única que resultará na afirmação de sua identidade. A anticoncepção é um tema importante, especialmente na adolescência, considerando a relevância social conferida pela ocorrência de gravidez nessa faixa etária. Quanto ao risco, a gravidez na adolescência apresenta maior probabilidade de ocasionar distúrbios psicológicos, hipertensivos e nutricionais, além disso, maior taxa de mortalidade infantil é evidenciada entre as crianças nascidas de mães adolescentes; destacando-se ainda o baixo peso ao nascer, restrição de crescimento fetal e prematuridade (Pereira et al., 2020).

Segundo Alencar, Silva, Silva, e Diniz, (2008), a adolescência é a fase de transição entre a infância e a idade adulta, marcada por transformações anatômicas, fisiológicas, psicológicas e sociais. É nesse período que ocorre o encontro de um núcleo de permanência e de estabilidade em si mesmo, denominado identidade, e sua busca por parte dos jovens pode produzir uma série de manifestações inquietantes, entre elas aquelas relacionadas ao exercício da sexualidade.

Acredita-se que o crescente aumento de adolescentes iniciando a vida sexual precocemente se dá ao fato da uma grande demanda de falta de informação. Muitas vezes os pais não possuem informações ou se sentem constrangidos em tratar determinados assuntos com os filhos, deixando a desejar no seu papel de educador ao desconsiderar tais assuntos tão 
importantes. Sendo assim, a partir do momento em que a família deixa de passar ao jovem uma orientação sexual adequada, ele fica em desvantagem (Varela, \& Borges, 2015).

A população adolescente hoje é sexualmente ativa e demanda cuidados preventivos com relação à saúde reprodutiva, principalmente devido à necessidade de reduzir consequências negativas da prática sexual insegura, devendo os serviços de saúde estar adequadamente preparados para receber e resolver a necessidade dos jovens. A iniciação sexual de forma cada vez mais precoce aumenta a preocupação com a saúde desse grupo, especialmente, os de baixa escolaridade e menor idade, que, ao iniciar a vida sexual precocemente, possui menos conhecimento sobre os métodos anticoncepcionais (Araújo, \& Nery, 2018).

A gravidez precoce afeta negativamente as oportunidades educacionais e econômicas. Além disso, mulheres com menor nível de escolaridade têm maiores riscos de resultados adversos durante a gravidez, bem como são menos experientes quanto às atividades de prevenção em saúde e planejamento familiar, estando seus filhos mais expostos ao risco de mortalidade. Vários fatores sociais e biológicos influenciam as chances de gravidez na adolescência, como exposição a condições adversas durante a infância e adolescência, história familiar de gravidez na adolescência, instabilidade familiar e baixos níveis educacionais. Considera-se também que mães adolescentes são menos propensas a frequentar as consultas de prénatal, aumentando o risco de partos prematuros (Araújo, \& Nery, 2018).

A ocorrência de gravidez não planejada constitui um indicador de falha na saúde reprodutiva, que pode ser decorrente de múltiplos fatores, como sexo sem proteção, uso incorreto e descontínuo dos métodos contraceptivos, dificuldades na negociação com o parceiro para o uso do preservativo, além do acesso precário à informação e aos métodos contraceptivos. Dessa forma, o objetivo deste trabalho foi avaliar fatores associados ao planejamento de gravidez na adolescência. Para isso, partiu-se da hipótese de que o conhecimento sobre métodos contraceptivos pode influenciar o planejamento da gravidez na adolescência (Araújo, \& Nery, 2018).

A vivência da sexualidade, nesse período, torna-se mais evidente e em geral manifesta-se através de práticas sexuais desprotegidas, devido à falta de informação, de comunicação entre familiares e de alguns mitos, tabus, ou mesmo pelo fato de ter medo de assumir sua própria sexualidade. Dessa forma, a procura e a curiosidade por novas experiências e a falta de orientações sobre as mudanças pelas quais estão passando tornam os adolescentes vulneráveis a situações de risco, dentre as quais as Infecções Sexualmente Transmissíveis (IST), incluindo a Síndrome da Imunodeficiência Adquirida (AIDS) (Almeida et al., 2017).

O desafio de enfrentar uma gravidez na adolescência é também evidenciado pela rápida mudança da situação de filha para mãe. Não havendo por grande parte das adolescentes um preparo físico, psicológico, social e econômico, comprometendo as condições para assumir de forma adequada este papel, que muitas vezes ainda está associado com a reprovação familiar contribuindo para que muitas fujam de casa e/ou abandonem os estudos, sem contar ainda que muitas são abandonadas pelos parceiros. Essas perdas vão influenciar emocionalmente a adolescente, podendo fazer com que estes eventos afetem-na psicologicamente colocando em risco a gestação saudável (Varela, \& Borges, 2015).

Pode-se considerar que a gravidez na adolescência como um bloqueio social, bem como um grande problema de saúde pública por causa das complicações que ela pode causar, algum dos problemas que podem ser causados são as evasões escolares, a reprovação da família, o incentivo ao aborto pela família e pelo companheiro. A adolescente ainda pode ter que lidar com o abandono do parceiro, o que é um fato muito comum, além da discriminação social e gravidez de risco. Este último fator geralmente está associado a um pré-natal inadequado (Varela, \& Borges, 2015).

A gravidez na adolescência é considerada como um fato precoce para essa etapa da vida, resultando em sérias implicações, como abandono das atividades escolares, riscos para o feto e para a mãe, conflitos familiares, discriminação social, afastamento de grupos de convivência, adiamento ou destruição de sonhos e planos. Sentimentos de perda, tristeza, 
solidão, isolamento, preocupações, além de desemprego ou ingresso no mercado de trabalho não qualificado podem surgir em consequência da gestação na adolescência (Fiedler, Araújo, \& Souza, 2015).

A assistência ao planejamento familiar orienta-se por ações preventivas e educativas, pela garantia do acesso igualitário às informações, métodos e técnicas disponíveis para regulação da fecundidade, devendo atender às reais necessidades da população feminina e masculina em idade fértil, através da utilização dos conhecimentos técnicos - científicos existentes e dos meios e recursos mais adequados e disponíveis. Contudo, a baixa qualidade da assistência em planejamento familiar reflete no aumento da fecundidade na adolescência, bem como em grande número de abortos que ocorrem no Brasil, dos quais uma significativa proporção é induzida e contribui para altas taxas de mortalidade materna (Bié, Diógenes, \& Moura, 2005).

De acordo com Carvalho (2012), o enfermeiro, bem como outros profissionais de saúde, tem papel fundamental para propiciar o conhecimento adequado sobre os métodos contraceptivos, sendo as atividades de educação em saúde uma importante ferramenta para seu alcance. Assim, torna-se imprescindível saber qual o nível de conhecimento dos adolescentes sobre métodos contraceptivos e sua adesão, a fim de que se possam fundamentar as estratégias e ações preventivas e/ou assistenciais que envolvem essa temática, considerando as peculiaridades dessa fase da vida.

Diante da temática em discussão, surge como questão norteadora do estudo: "Qual conhecimento e uso da contracepção na adolescência: contribuições da assistência de enfermagem"? Assim, o objetivo do presente estudo é analisar as evidências científicas publicadas sobre o conhecimento e uso da contracepção na adolescência: contribuições da assistência de enfermagem.

A realização do presente estudo relacionado à temática, é essencial para a construção coletiva do conhecimento, pois, o estudo possibilita a sociedade acadêmica e cientifica a ampliar o conhecimento sobre as contribuições da assistência de enfermagem no conhecimento e uso da contracepção na adolescência: contribuições da assistência de enfermagem. Desse modo, o estudo trará contribuições pertinentes, na medida em que acrescentará as evidências científicas discussões relevantes a respeito dessa temática tão importante.

\section{Metodologia}

O presente estudo trata de uma revisão bibliográfica do método revisão integrativa da literatura, realizado nos meses entre março a agosto de 2021. A revisão configura-se, portanto, como um tipo de revisão da literatura que reúne achados de estudos desenvolvidos mediante diferentes metodologias, permitindo aos revisores sintetizar resultados sem ferir a filiação epistemológica dos estudos empíricos incluídos. Para que esse processo concretize-se de maneira lógica, isenta de desatinos epistemológicos, a revisão requer que os revisores procedam à análise e à síntese dos dados primários de forma sistemática e rigorosa (Soares et al., 2014).

A revisão da literatura serve para reconhecer a unidade e a diversidade interpretativa existente no eixo temático em que se insere o problema em estudo, para ampliar, ramificar a análise interpretativa, bem como para compor as abstrações e sínteses que qualquer pesquisa requer colaborando para a coerência nas argumentações do pesquisador. Nesse sentido, a revisão integrativa é um método que tem como finalidade reunir e sintetizar resultados de pesquisas sobre um delimitado tema ou questão, de maneira sistemática e ordenada e abrangente, contribuindo para o aprofundamento do conhecimento do tema investigado (Ferenhof \& Fernandes, 2016).

O processo de revisão da literatura requer a elaboração de uma síntese pautada em diferentes tópicos, capazes de criar uma ampla compreensão sobre o conhecimento. A revisão da literatura é um primeiro passo para a construção do conhecimento científico, pois é através desse processo que novas teorias surgem, bem como são reconhecidas lacunas e oportunidades para o surgimento de pesquisas num assunto específico (Botelho, Cunha, \& Macedo, 2011). 
A revisão integrativa é uma ferramenta de investigação que permite à procura, a avaliação crítica e a síntese de evidências disponíveis sobre o tema investigado, em que o produto final é o estado do conhecimento, a implementação de intervenções efetivas na prestação de cuidados e na redução de custos. Além disso, permite a identificação de fragilidades, que poderão conduzir ao desenvolvimento de futuras investigações (Sousa, Marques-Vieira, Severino, \& Antunes, 2017).

A revisão integrativa permite que o leitor reconheça os profissionais que mais investigam determinado assunto, separar o achado científico de opiniões e ideias, além de descrever o conhecimento no seu estado atual, promovendo impacto sobre a prática clínica. Este método de pesquisa proporciona aos profissionais de saúde dados relevantes de um determinado assunto, em diferentes lugares e momentos, mantendo-os atualizados e facilitando as mudanças na prática clínica como consequência da pesquisa. Dessa forma, acredita-se que a revisão integrativa é uma ferramenta importante no processo de comunicação dos resultados de pesquisas, facilitando a utilização desses na prática clínica, uma vez que proporciona uma síntese do conhecimento já produzido e fornece subsídios para a melhoria da assistência à saúde (Mendes, Silveira, \& Galvão, 2008).

Figura 1. Fluxograma fases distintas da revisão integrativa.

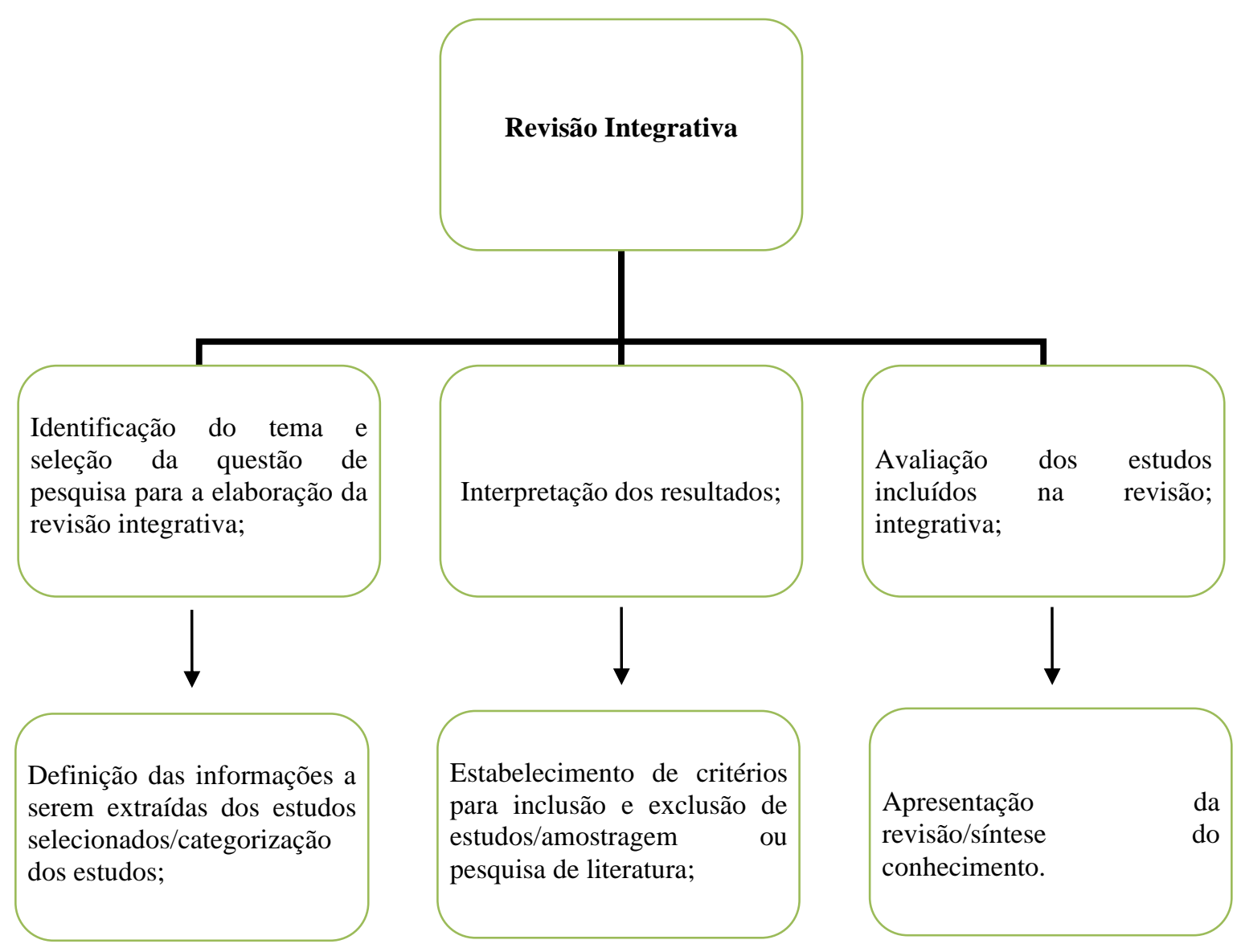

Fonte: Mendes, Silveira, Galvão (2008).

A revisão integrativa é um tipo de pesquisa que fornece informações mais amplas de maneira sistemática, ordenada e abrangente, sobre um assunto ou tema, com a finalidade de sintetizar resultados obtidos em pesquisa sobre temas ou questões. A definição das informações a serem extraídas dos estudos selecionados por categorização; avaliação dos estudos incluídos; interpretação dos resultados; e apresentação da revisão/síntese do conhecimento (Ercole, Melo, \& Alcoforado, 2015).

Estudo elaborado com abordagem qualitativa tornando-se importante a interpretação por parte do pesquisador com suas opiniões sobre o fenômeno em estudo. Neste tipo de pesquisa destacam-se algumas características como: a pesquisa 
qualitativa, em geral, ocorre no ambiente natural com coleta direta de dados e o pesquisador é o principal instrumento; os dados coletados são preferencialmente descritivos; a preocupação do processo é predominante em relação à do produto; a análise de dados e informações tende a seguir um processo indutivo (Pereira, Shitsuka, Parreira, \& Shitsuka, 2018).

A pesquisa qualitativa envolve uma abordagem interpretativa do mundo, o que significa que seus pesquisadores estudam as coisas em seus cenários naturais, tentando entender os fenômenos em termos dos significados que as pessoas a eles conferem. A pesquisa qualitativa atribui importância fundamental aos depoimentos dos atores sociais envolvidos, aos discursos e aos significados transmitidos por eles. Nesse sentido, esse tipo de pesquisa preza pela descrição detalhada dos fenômenos e dos elementos que o envolvem (Augusto, Souza, Dellagnelo, \& Cario, 2014).

De acordo com Souza, Silva, e Carvalho (2010), a ser realizada nas seguintes etapas: 1- Elaboração da pergunta norteadora; 2- Busca nas bases de dados e amostragem; 3- Coleta de dados, 4- Análise crítica.

Para responder à questão norteadora do estudo: "Qual conhecimento e uso da contracepção na adolescência: contribuições da assistência de enfermagem"? Aplicou-se os descritores/palavras-chaves: "Cuidados de Enfermagem", “Anticoncepcionais", “Adolescente”, "Educação em Saúde”.

A busca efetuou-se, através da Plataforma da Biblioteca Virtual em Saúde - BVS, utilizando as bases de dados Literatura Latino-Americana e do Caribe em Ciências da Saúde (LILACS), Base de Dados de Enfermagem (BDENF), por meio da - Scientific Electronic Library Online (SCIELO). Aderindo-se através dos descritores/palavras chaves: "Cuidados de Enfermagem”, “Anticoncepcionais", “Adolescente”, "Educação em Saúde”, combinados com o operador booleano “AND”.

Os critérios de inclusão estabelecidos foram: artigos originais disponibilizados na íntegra, completos, que abrangessem a temática e na forma online, publicados nos idiomas português, inglês e espanhol, publicações que respondiam a questão norteadora do estudo. Os critérios de exclusão estabelecidos na seleção foram: artigos incompletos, artigos duplicados, teses, dissertações, monografias, manuais, e publicações que não estavam de acordo com a questão norteadora do estudo. No início da pesquisa obteve-se 7756 publicações, após a aplicação dos critérios de inclusão e exclusão totalizou-se parcialmente 295 artigos, depois de uma leitura mais precisa aderiu-se um total final de 27 publicações de acordo para serem trabalhadas na elaboração do referido estudo.

O fluxograma representado abaixo, caracteriza a estratégia de coleta de dados utilizada pelos autores, no sentido de detalhar as principais evidencias encontradas no estudo. 
Figura 2. Fluxograma Estratégia de Busca - Bases de Dados, Teresina-PI, Brasil, 2021.

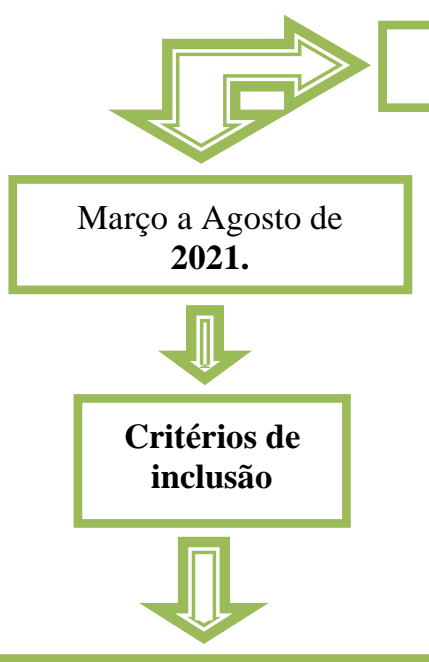

Artigos originais disponibilizados na íntegra, completos, que abrangessem a temática e na forma online, publicados nos idioma português, inglês e espanhol, publicações que respondiam a questão norteadora do estudo.

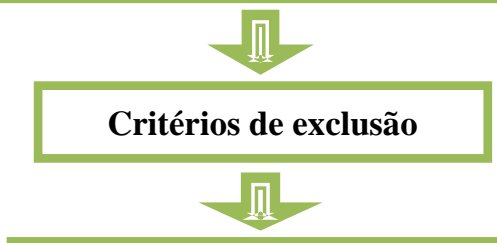

Artigos incompletos, artigos duplicados, teses, dissertações, monografias, manuais, e publicações que não estavam de acordo com a questão norteadora do estudo
Estratégia de Busca Revisão Integrativa

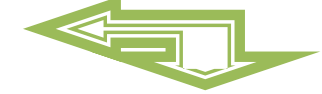

Descritores/Palavras chaves:
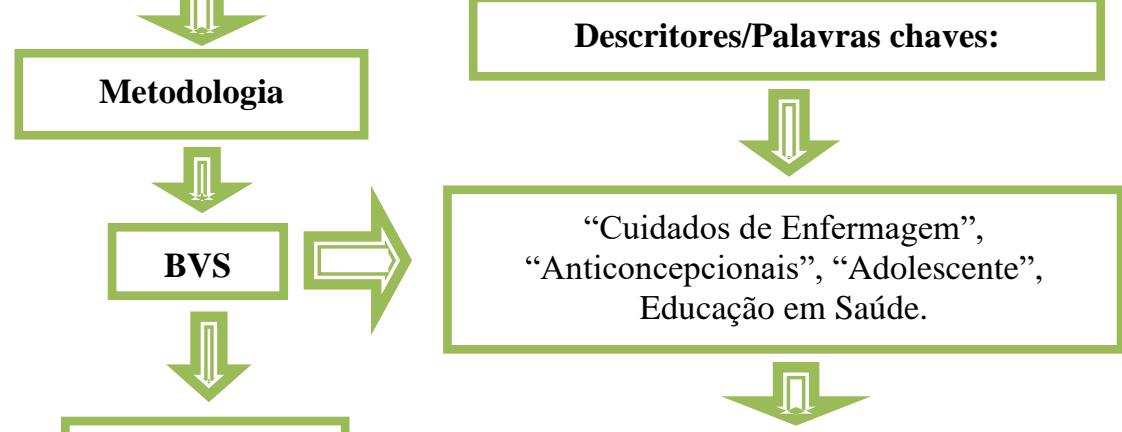

"Cuidados de Enfermagem",

"Anticoncepcionais", "Adolescente", Educação em Saúde.
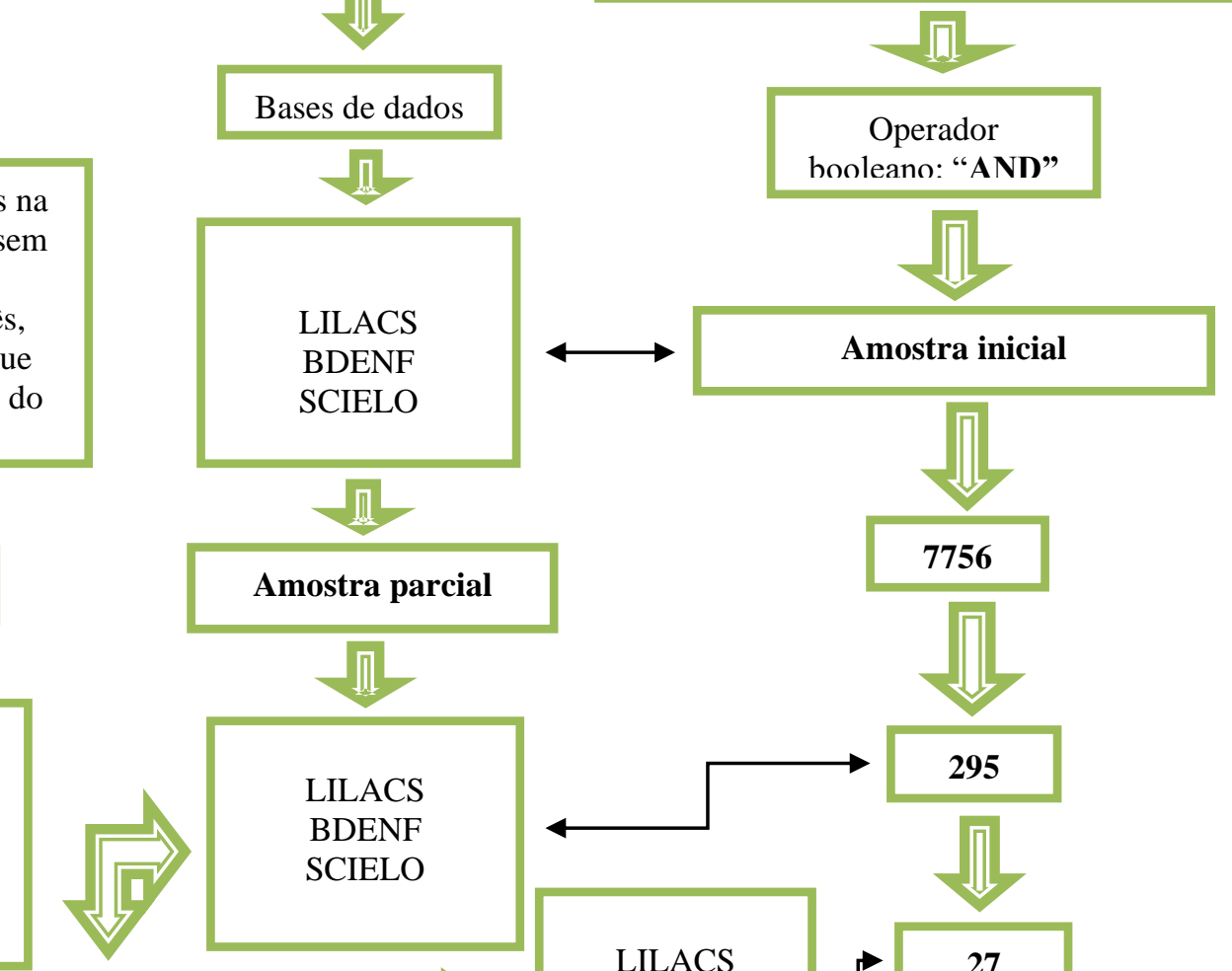

Amostra final
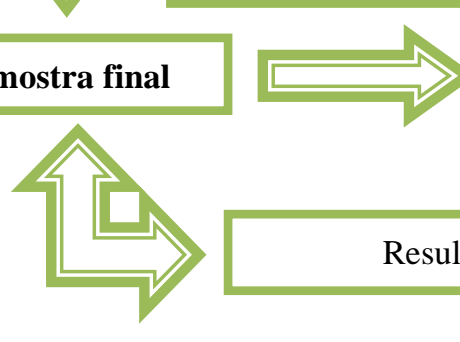

Resultado final: $\mathbf{2 7}$

LILACS

BDENF

SCIELO

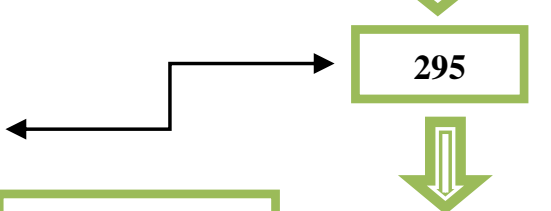

BDENF

SCIELO
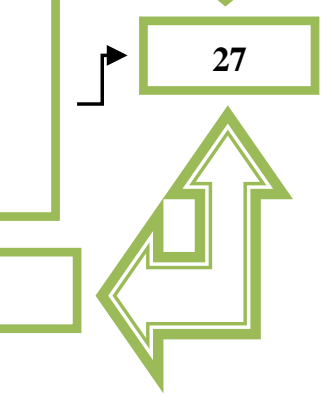

Fonte: Autores (2021).

No Fluxograma 2, estão expostos a estratégia de busca, bases de dados, período de realização do estudo, critérios de inclusão e exclusão, amostra inicial, parcial e final, de acordo com a quantidade de artigos que irão compor os resultados do estudo.

O presente estudo assegura os aspectos éticos, garantindo a autoria dos artigos pesquisados, utilizando para as citações e referências dos autores as normas APA. Os preceitos éticos estabelecidos no que se refere a zelar pela legitimidade das informações, privacidade e sigilo das informações, quando necessárias, tornando os resultados desta pesquisa públicos. Os pesquisadores buscaram a legitimidade e fidelidade nas citações dos autores seja nas citações diretas ou parafraseadas no estudo. 


\section{Resultados e Discussão}

Diante dos resultados obtidos no estudo por meio da estratégia de busca, os autores delinearam variáveis para melhor descrever as evidências encontradas na pesquisa. O quadro a seguir caracteriza os artigos com base nas variáveis propostas: número do artigo, base de dados, periódico, autor e ano de publicação, tipo de estudo, título, objetivo, resultados em evidências e conclusões importantes.

Quadro 1. Caracterização dos artigos selecionados para o estudo.

\begin{tabular}{|c|c|c|c|c|c|c|c|}
\hline $\mathbf{N}$ & $\begin{array}{l}\text { Base de } \\
\text { Dados }\end{array}$ & Periódico & $\begin{array}{c}\text { Autor e } \\
\text { Ano }\end{array}$ & $\begin{array}{l}\text { Tipo de } \\
\text { Estudo }\end{array}$ & Título & Objetivo & $\begin{array}{c}\text { Resultados em evidências e conclusões } \\
\text { importantes }\end{array}$ \\
\hline 1 & BDENF & $\begin{array}{l}\text { R. Pesq: } \\
\text { Cuid. } \\
\text { Fundam. } \\
\text { Online. }\end{array}$ & $\begin{array}{l}\text { Kempfer, } \\
\text { Fraga, } \\
\text { Mafra, } \\
\text { Hoffman, } \\
\quad \& \\
\text { Lazzari, } \\
2012 .\end{array}$ & $\begin{array}{c}\text { Estudo } \\
\text { qualitativo - } \\
\text { descritivo, } \\
\text { convergente- } \\
\text { assistencial. }\end{array}$ & $\begin{array}{l}\text { Contracepção na } \\
\text { adolescência: uma } \\
\text { questão } \\
\text { autocuidado. }\end{array}$ & \begin{tabular}{lr}
\multicolumn{2}{l}{ Sensibilizar adoles- } \\
centes sobre \\
importância & do \\
autocuidado & na \\
prevenção & da \\
gravidez. &
\end{tabular} & $\begin{array}{l}\text { Considera-se que os conhecimentos } \\
\text { durante as atividades educativas tanto na } \\
\text { escola, quanto no centro de saúde são } \\
\text { importantes para o autocuidado a saúde } \\
\text { sexual e reprodutiva, mas insuficientes } \\
\text { para mudar o comportamento deste grupo } \\
\text { quanto à adoção de práticas sexuais } \\
\text { seguras. }\end{array}$ \\
\hline 2 & LILACS & $\begin{array}{l}\text { Online } \\
\text { Brazilian } \\
\text { Journal Of } \\
\text { Nursing. }\end{array}$ & $\begin{array}{l}\text { Brasil, } \\
\text { Queiroz, } \\
\text { \& Cunha, } \\
2012 .\end{array}$ & $\begin{array}{l}\text { Estudo qualita- } \\
\text { tivo. }\end{array}$ & $\begin{array}{lr}\text { Acolhimento à } \\
\text { adolescente na } \\
\text { consulta de } \\
\text { enfermagem - } \\
\text { estudo qualita- } \\
\text { tivo. }\end{array}$ & $\begin{array}{lr}\text { Compreender } & \text { a } \\
\text { relação do enfermeiro } \\
\text { com a } & \text { mãe } \\
\text { adolescente } & \text { na } \\
\text { consulta } & \text { de } \\
\text { puericultura } & \text { sob } \\
\text { enfoque } & \text { do } \\
\text { acolhimento. } & \end{array}$ & $\begin{array}{l}\text { Geralmente, a gravidez na adolescência é } \\
\text { dos principais problemas de saúde pública } \\
\text { no Brasil, ficando a jovem e seu filho } \\
\text { vulneráveis a riscos físicos, psicológicos e } \\
\text { sociais. A gestação nesta população nem } \\
\text { sempre é planejada, e algumas vezes não } \\
\text { desejada pela gestante, seu companheiro e } \\
\text { sua família de origem. No entanto, é um } \\
\text { acontecimento que pode ter seus riscos } \\
\text { minimizados, quando acompanhada por } \\
\text { uma equipe de saúde responsável pelo } \\
\text { atendimento pré-natal. }\end{array}$ \\
\hline 3 & BDENF & $\begin{array}{l}\text { Cogitare } \\
\text { Enferm. }\end{array}$ & $\begin{array}{l}\text { Rodrigue } \\
\text { s, \& } \\
\text { Jardim, } \\
2012 \text {. }\end{array}$ & $\begin{array}{l}\text { Estudo } \\
\text { descritivo } \\
\text { exploratório. }\end{array}$ & $\begin{array}{lr}\text { Conhecimento } & \text { e } \\
\text { uso } & \text { da } \\
\text { contracepção } & \text { de } \\
\text { emergência } & \text { na } \\
\text { adolescência: } & \\
\text { contribuições } & \text { para } \\
\text { a enfermagem. }\end{array}$ & $\begin{array}{lr}\text { Identificar } & \text { o } \\
\text { conhecimento e o uso } \\
\text { da contracepção de } \\
\text { emergência entre } \\
\text { adolescentes. }\end{array}$ & $\begin{array}{l}\text { Cabe ao enfermeiro, como educador } \\
\text { atuante em unidades básicas de saúde, } \\
\text { escolas e outros espaços sociais, } \\
\text { desenvolver estratégias para alcançar esta } \\
\text { população e contribuir para o } \\
\text { conhecimento, a prevenção da gravidez } \\
\text { indesejada e promoção do autocuidado. }\end{array}$ \\
\hline 4 & SCIELO & $\begin{array}{l}\text { Esc Anna } \\
\text { Nery Rev } \\
\text { Enferm. }\end{array}$ & $\begin{array}{c}\text { Gurgel, } \\
\text { Alves, } \\
\text { Vieira, } \\
\text { Pinheiro, } \\
\& \\
\text { Barroso, } \\
2008 .\end{array}$ & $\begin{array}{c}\text { Estudo } \\
\text { exploratório, } \\
\text { descritivo. }\end{array}$ & $\begin{array}{lr}\text { Gravidez } & \text { na } \\
\text { adolescência: } & \text { ten- } \\
\text { dência } & \text { na } \\
\text { produção } & \text { cientí- } \\
\text { fica } & \text { de } \\
\text { enfermagem. } & \end{array}$ & $\begin{array}{lr}\text { Identificar } & \text { as } \\
\text { concepções } & \text { da } \\
\text { gravidez na } & \text { na } \\
\text { adolescência, sujeito, } \\
\text { vulnerabilidade re } \\
\text { gênero, presentes na } \\
\text { produção científica de } \\
\text { enfermagem. }\end{array}$ & $\begin{array}{l}\text { A prevenção da gravidez na adolescência } \\
\text { é uma responsabilidade de cada } \\
\text { componente da equipe da saúde e vai } \\
\text { além de aprimorar a escuta, fortalecer os } \\
\text { vínculos, garantir o acesso às informações } \\
\text { e aos métodos anticoncepcionais. São de } \\
\text { indescartável relevância } \\
\text { intersetorialidade e as ações coletivas para } \\
\text { a promoção e desenvolvimento de atitudes } \\
\text { e habilidades nos adolescentes para lidar } \\
\text { com a sexualidade, aumentando o seu } \\
\text { poder de decisão para não ceder às } \\
\text { pressões, ampliar a força de negociação, } \\
\text { desenvolver o autocuidado, ampliar o } \\
\text { acesso a atividades educativas e } \\
\text { recreativas e estimular o protagonismo. }\end{array}$ \\
\hline 5 & SCIELO & $\begin{array}{c}\text { Revista Pró } \\
- \\
\text { UniverSUS } \\
\text {. }\end{array}$ & $\begin{array}{l}\text { Ribeiro } \\
\text { et al., } \\
2017 .\end{array}$ & $\begin{array}{c}\text { Estudo } \\
\text { qualitativo de } \\
\text { caráter } \\
\text { descritivo. }\end{array}$ & $\begin{array}{ll}\text { Práticas } & \\
\text { educativas } & \text { do } \\
\text { enfermeiro } & \text { na } \\
\text { prevenção } & \text { da } \\
\text { gravidez } & \text { na } \\
\text { adolescência: } & \\
\text { estratégias } & \text { e } \\
\text { perspectivas. } & \end{array}$ & $\begin{array}{l}\text { Descrever as práticas } \\
\text { educativas realizadas } \\
\text { pelo enfermeiro na } \\
\text { prevenção da gravidez } \\
\text { na adolescência; e } \\
\text { analisar como tais } \\
\text { ações podem } \\
\text { estimular a adesão de } \\
\text { adolescentes no } \\
\text { serviço no de } \\
\text { planejamento } \\
\text { reprodutivo. }\end{array}$ & $\begin{array}{l}\text { O período da adolescência é envolto por } \\
\text { diversos fatores que podem torná-lo } \\
\text { conflituoso devido à necessidade de } \\
\text { reajuste de sua identidade no meio social. } \\
\text { A gestação nessa fase potencializa essas } \\
\text { mudanças e reajustes. A adolescente } \\
\text { grávida tende a evadir-se da escola e por } \\
\text { consequência submeter-se a subempregos } \\
\text { perpetuando assim a pobreza. }\end{array}$ \\
\hline
\end{tabular}




\begin{tabular}{|c|c|c|c|c|c|c|c|}
\hline 6 & SCIELO & $\begin{array}{l}\text { Uniedu. } \\
\text { Sed. }\end{array}$ & $\begin{array}{c}\text { Varela, \& } \\
\text { Borges, } \\
2015 .\end{array}$ & $\begin{array}{l}\text { Estudo } \\
\text { qualitativo } \\
\text { descritivo, } \\
\text { convergente- } \\
\text { assistencial. }\end{array}$ & $\begin{array}{l}\text { Perfil e } \\
\text { conhecimento } \\
\text { sobre médotos } \\
\text { anticoncepcionais } \\
\text { de adolescentes } \\
\text { grávidas. }\end{array}$ & $\begin{array}{l}\text { Identificar o perfil das } \\
\text { adolescentes grávidas } \\
\text { bem como a vivência } \\
\text { em relação ao uso } \\
\text { prévio de métodos } \\
\text { anticoncepcionais. }\end{array}$ & $\begin{array}{l}\text { Nota-se a importância que não deve-se } \\
\text { deixar de considerar que o processo da } \\
\text { adolescência marca muitas } \\
\text { transformações sexuais que asseguram a } \\
\text { possibilidade de reprodução e preservação } \\
\text { da espécie. Mas as mudanças corporais e } \\
\text { de comportamento dizem também respeito } \\
\text { às novas descobertas emocionais e sociais. } \\
\text { mesmo havendo grande quantidade de } \\
\text { informações, elas são insuficientes diante } \\
\text { das fantasias e dos desejos sexuais. }\end{array}$ \\
\hline 7 & SCIELO & $\begin{array}{l}\text { Researchga } \\
\text { te.net. }\end{array}$ & $\begin{array}{l}\text { Timbó et } \\
\text { al., } 2014 .\end{array}$ & $\begin{array}{c}\text { Estudo } \\
\text { exploratório, } \\
\text { descritivo, } \\
\text { qualitativo. }\end{array}$ & $\begin{array}{l}\text { Saúde reproduti- } \\
\text { va: percepção de } \\
\text { adolescentes de } \\
\text { um município do } \\
\text { Estado do Ceará, } \\
\text { Brasil. }\end{array}$ & $\begin{array}{l}\text { Conhecer a percepção } \\
\text { de adolescentes de } \\
\text { uma cidade da Zona } \\
\text { Norte do Estado do } \\
\text { Ceará, acerca do } \\
\text { planejamento repro- } \\
\text { dutivo. }\end{array}$ & $\begin{array}{l}\text { A gravidez na adolescência é um } \\
\text { problema de saúde pública, tanto no } \\
\text { Brasil como em muitos outros países. Para } \\
\text { entender os possíveis fatores etiológicos } \\
\text { ligados ao incremento das gestações nessa } \\
\text { faixa etária, é preciso perceber a } \\
\text { complexidade e a multicasualidade desses } \\
\text { fatores, que tornaram os adolescentes } \\
\text { especialmente vulneráveis a essa situação. }\end{array}$ \\
\hline 8 & SCIELO & $\begin{array}{l}\text { Cogitare } \\
\text { Enferm. }\end{array}$ & $\begin{array}{l}\text { Araújo, } \\
\text { \& Nery, } \\
2018 .\end{array}$ & $\begin{array}{c}\text { Estudo } \\
\text { transversal. }\end{array}$ & $\begin{array}{l}\text { Conhecimento so- } \\
\text { bre contracepção e } \\
\text { fatores associados } \\
\text { ao planejamento } \\
\text { de gravidez na } \\
\text { adolescência. }\end{array}$ & $\begin{array}{l}\text { Avaliar } \\
\text { conhecimento de } \\
\text { adolescentes sobre } \\
\text { práticas contracepti - } \\
\text { vas e sua associação } \\
\text { com gravidez não } \\
\text { planejada. }\end{array}$ & $\begin{array}{l}\text { O conhecimento não é o único fator } \\
\text { responsável, } \\
\text { significativamente para o desfecho da } \\
\text { gravidez não planejada, considerando que } \\
\text { o fato de a adolescente não saber utilizar a } \\
\text { pílula do dia seguinte aumenta em } 3,93 \\
\text { vezes a chance de ter uma gravidez não } \\
\text { planejada. }\end{array}$ \\
\hline 9 & LILACS & $\begin{array}{l}\text { Revista } \\
\text { Eletrônica } \\
\text { Acervo } \\
\text { Saúde / } \\
\text { Electronic } \\
\text { Journal } \\
\text { Collection } \\
\text { Health. }\end{array}$ & $\begin{array}{l}\text { Pereira et } \\
\text { al., } 2019 .\end{array}$ & $\begin{array}{c}\text { Estudo } \\
\text { descritivo, } \\
\text { do tipo relato } \\
\text { de experiência. }\end{array}$ & $\begin{array}{l}\text { Educação em } \\
\text { saúde com } \\
\text { adolescentes } \\
\text { escolares acerca } \\
\text { da sexualidade e } \\
\text { infecções sexual- } \\
\text { mente transmissí- } \\
\text { veis: um relato de } \\
\text { experiência. }\end{array}$ & 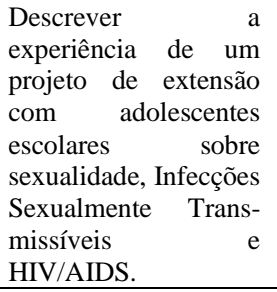 & $\begin{array}{l}\text { Evidencia-se a importância de atividades } \\
\text { educativas na adolescência que tenham } \\
\text { como base as temáticas trabalhadas, } \\
\text { visando à promoção da saúde por meio de } \\
\text { métodos que favoreçam a prática da } \\
\text { sexualidade de maneira segura e saudável. }\end{array}$ \\
\hline 10 & SCIELO & $\begin{array}{l}\text { Rev Bras } \\
\text { Enferm. }\end{array}$ & $\begin{array}{l}\text { Almeida } \\
\text { et al., } \\
2017 .\end{array}$ & $\begin{array}{c}\text { Estudo } \\
\text { qualitativo, } \\
\text { descritivo. }\end{array}$ & $\begin{array}{l}\text { Conhecimento de } \\
\text { adolescentes rela- } \\
\text { cionados às } \\
\text { doenças sexual- } \\
\text { mente transmissí- } \\
\text { veis e gravidez. }\end{array}$ & $\begin{array}{l}\text { Investigar } r \\
\text { conhecimento de } \\
\text { adolescentes relacio- } \\
\text { nado às Infecções } \\
\text { Sexualmente Trans- } \\
\text { missíveis (IST), AIDS } \\
\text { e gravidez, além de } \\
\text { conhecer } \\
\text { compreensão sobre o } \\
\text { papel da escola na } \\
\text { educação sexual. }\end{array}$ & $\begin{array}{l}\text { Revela-se a necessidade de ações } \\
\text { educativas de prevenção para os } \\
\text { adolescentes, pois a falta de informações } \\
\text { contribui para a sua vulnerabilidade. Os } \\
\text { adolescentes reconhecem a importância da } \\
\text { educação sexual; consequentemente, é } \\
\text { importante a implementação de estratégias } \\
\text { de promoção e de proteção à saúde no } \\
\text { ambiente escolar para contribuir e } \\
\text { fortalecer o autocuidado na saúde. }\end{array}$ \\
\hline 11 & SCIELO & $\begin{array}{l}\text { Revista } \\
\text { Brasileira } \\
\text { em } \\
\text { Promoção } \\
\text { da Saúde. }\end{array}$ & $\begin{array}{c}\text { Bié, } \\
\text { Diógenes } \\
\text { \&\& } \\
\text { Moura, } \\
2006 .\end{array}$ & $\begin{array}{c}\text { Estudo } \\
\text { qualitativo, } \\
\text { descritivo. }\end{array}$ & $\begin{array}{l}\text { Planejamento fa- } \\
\text { miliar: o que os } \\
\text { adolescentes sa- } \\
\text { bem sobre este } \\
\text { assunto. }\end{array}$ & $\begin{array}{l}\text { Identificar } \\
\text { conhecimento de } \\
\text { adolescentes sobre } \\
\text { planejamento familiar } \\
\text { e métodos } \\
\text { contraceptivos; des- } \\
\text { crever as fontes de } \\
\text { informações sobre o } \\
\text { assunto e verificar os } \\
\text { benefícios da } \\
\text { educação sexual com } \\
\text { adolescentes. }\end{array}$ & $\begin{array}{l}\text { Os adolescentes demonstraram pouco } \\
\text { conhecimento sobre as especificidades } \\
\text { dos diferentes tipos de contraceptivos, } \\
\text { sendo o preservativo masculino o mais } \\
\text { conhecido e mais eficaz. As formas de } \\
\text { obtenção de informações sobre os } \\
\text { anticoncepcionais assinaladas pelos } \\
\text { adolescentes foram: a televisão, as } \\
\text { revistas e os próprios amigos. As } \\
\text { atividades grupais ampliaram o } \\
\text { conhecimento dos jovens. Reforça-se a } \\
\text { necessidade de expandir a educação } \\
\text { sexual para os jovens, livre de atitudes } \\
\text { preconceituosas. }\end{array}$ \\
\hline 12 & SCIELO & $\begin{array}{l}\text { Internationa } \\
1 \text { Journal of } \\
\text { Developme } \\
\text { ntal and } \\
\text { Educational } \\
\text { Psychology }\end{array}$ & $\begin{array}{l}\text { Brás, } \\
\text { Anes, } \\
\text { Praça, \& } \\
\text { Morais, } \\
2011 .\end{array}$ & $\begin{array}{l}\text { Estudo de } \\
\text { cariz misto } \\
\text { (quantitativo } \\
\text { com um cunho } \\
\text { qualitativo), } \\
\text { exploratório, } \\
\text { descritivo, } \\
\text { analítico e } \\
\text { transversal. }\end{array}$ & $\begin{array}{l}\text { Os adolescentes e } \\
\text { a sexualidade: } \\
\text { assuntos da } \\
\text { procura dos } \\
\text { cuidados de saúde } \\
\text { primários. }\end{array}$ & \begin{tabular}{lr}
\multicolumn{2}{l}{ Conhecer as } \\
colocadas & pelos \\
adolescentes & aos \\
enfermeiros & dos \\
cuidados de & saúde \\
primários, no sentido \\
de facilitar a tomada \\
de decisão \\
intervenção ao nível \\
de uma sexualidade \\
saudável.
\end{tabular} & $\begin{array}{l}\text { A primeira experiência sexual dos jovens } \\
\text { adolescentes e a proporção de jovens } \\
\text { sexualmente activas, inicia-se hoje cada } \\
\text { vez mais precoce. Assim, quanto mais } \\
\text { cedo for o início das relações sexuais, } \\
\text { menos informados os jovens estarão, logo } \\
\text { menos provável será o uso de métodos } \\
\text { contraceptivos e, por consequência, maior } \\
\text { probabilidade de engravidar e/ou de } \\
\text { contrair doenças sexualmente } \\
\text { transmissíveis. }\end{array}$ \\
\hline
\end{tabular}




\begin{tabular}{|c|c|c|c|c|c|c|c|}
\hline 13 & BDENF & $\begin{array}{l}\text { R. Enferm. } \\
\text { Cent. O. } \\
\text { Min. }\end{array}$ & $\begin{array}{c}\text { Maia, } \\
\text { Ribeiro, } \\
\& \\
\text { Guimarãe } \\
\text { s, } 2011 .\end{array}$ & $\begin{array}{c}\text { Estudo } \\
\text { epidemiológi - } \\
\text { co, descritivo, } \\
\text { de caráter } \\
\text { exploratório. }\end{array}$ & $\begin{array}{lr}\text { Opção } & \text { contracep- } \\
\text { tiva } & \text { de } \\
\text { universitários da } \\
\text { região r centro- } \\
\text { oeste de minas } \\
\text { gerais. }\end{array}$ & $\begin{array}{l}\text { Fazer um } \\
\text { levantamento da } \\
\text { escolha do método } \\
\text { contraceptivo entre os } \\
\text { discentes da UFSJ. }\end{array}$ & $\begin{array}{l}\text { Os jovens têm sido considerados como } \\
\text { importante grupo populacional com } \\
\text { relação a risco epidemiológico para } \\
\text { infecções sexualmente transmissíveis } \\
\text { (ISTs). Com isso, campanhas de } \\
\text { prevenção realizadas pela Organização } \\
\text { das Nações Unidas definem essa faixa } \\
\text { etária como prioridade. A importância de } \\
\text { abordar essa temática está na associação } \\
\text { que se faz entre o comportamento na } \\
\text { primeira relação sexual juntamente com } \\
\text { os padrões comportamentais que podem } \\
\text { refletir por toda a vida, além da } \\
\text { identificação sobre o começo da prática } \\
\text { sexual por pessoas mais jovens que } \\
\text { podem ser consideradas como fator de } \\
\text { risco para a gravidez na adolescência e as } \\
\text { DSTs, incluindo o o Human } \\
\text { Immunodeficiency Virus (HIV). }\end{array}$ \\
\hline 14 & SCIELO & $\begin{array}{l}\text { Rev } \\
\text { Enferm } \\
\text { UFPE } \\
\text { Online. }\end{array}$ & $\begin{array}{c}\text { Santos, } \\
\text { Rodrigue } \\
\text { s, Araújo, } \\
\& \\
\text { Vasconce } \\
\text { los, } 2007 .\end{array}$ & $\begin{array}{c}\text { Estudo } \\
\text { exploratório, } \\
\text { descritivo, } \\
\text { quantitativo. }\end{array}$ & $\begin{array}{l}\text { Opinião de } \\
\text { adolescentes entre } \\
\text { os } 10 \text { aos } 14 \text { anos } \\
\text { sobre a pílula } \\
\text { anticoncepcional e } \\
\text { os preservativos } \\
\text { masculino e } \\
\text { feminino. }\end{array}$ & $\begin{array}{l}\text { Identificar a opinião } \\
\text { dos adolescentes de } \\
\text { um colégio público } \\
\text { federal da cidade de } \\
\text { Recife (PE) sobre } \\
\text { métodos contracepti- } \\
\text { vos, com enfoque na } \\
\text { pílula anticoncepcio- } \\
\text { nal e nos } \\
\text { preservativos mascu- } \\
\text { lino e feminino. }\end{array}$ & $\begin{array}{l}\text { As características dos adolescentes que } \\
\text { utilizam contraceptivos eficazmente } \\
\text { incluem uma alta condição sócio- } \\
\text { econômica, o conhecimento por parte de } \\
\text { um dos pais ou irmãos sobre o uso de } \\
\text { contraceptivos e uma experiência pessoal } \\
\text { ou de um amigo íntimo que vivenciou o } \\
\text { susto de uma gestação. Um segundo fator } \\
\text { que influencia a utilização eficaz do } \\
\text { contraceptivo é o ambiente da pessoa. A } \\
\text { família, a comunidade ou a religião pode } \\
\text { desaprovar ou proibir a contracepção. }\end{array}$ \\
\hline 15 & SCIELO & $\begin{array}{l}\text { Ciência \& } \\
\text { Educação. }\end{array}$ & $\begin{array}{l}\text { Alencar, } \\
\text { Silva, } \\
\text { Silva, \& } \\
\text { Diniz, } \\
2008 .\end{array}$ & $\begin{array}{c}\text { Estudo } \\
\text { experimental, } \\
\text { qualitativo. }\end{array}$ & 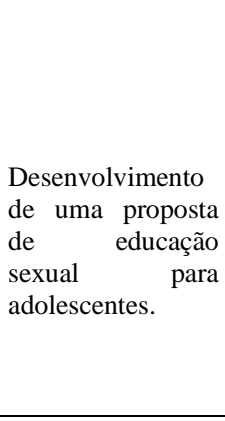 & $\begin{array}{lr}\text { Descrever } & \text { a } \\
\text { experiência } & \text { de } \\
\text { aplicação de uma } \\
\text { proposta pedagógica } \\
\text { no campo da } \\
\text { educação sexual, } \\
\text { visando atender } \\
\text { adolescentes de uma } \\
\text { comunidade carente } \\
\text { do interior paulista, } \\
\text { com foco em questões } \\
\text { sobre sexualidade e } \\
\text { DST/Aids. }\end{array}$ & $\begin{array}{l}\text { A adolescência é a fase de transição entre } \\
\text { a infância e a idade adulta, marcada por } \\
\text { transformações anatômicas, fisiológicas, } \\
\text { psicológicas e sociais. É nesse período } \\
\text { que ocorre o encontro de um núcleo de } \\
\text { permanência e de estabilidade em si } \\
\text { mesmo, denominado identidade, e sua } \\
\text { busca por parte dos jovens pode produzir } \\
\text { uma série de manifestações inquietantes, } \\
\text { entre elas aquelas relacionadas ao } \\
\text { exercício da sexualidade. }\end{array}$ \\
\hline 16 & SCIELO & $\begin{array}{l}\text { Brazilian } \\
\text { Journal Of } \\
\text { Health } \\
\text { Review. }\end{array}$ & $\begin{array}{l}\text { Santos, } \\
\text { Vador, } \\
\text { Cunha, \& } \\
\text { Silva, } \\
2020 .\end{array}$ & $\begin{array}{l}\text { Estudo } \\
\text { exploratório, } \\
\text { descritivo e } \\
\text { qualitativo. }\end{array}$ & $\begin{array}{ll}\text { Abordagem } & \text { do } \\
\text { enfermeiro } & \text { na } \\
\text { gravidez } & \text { na } \\
\text { adolescência. } & \end{array}$ & 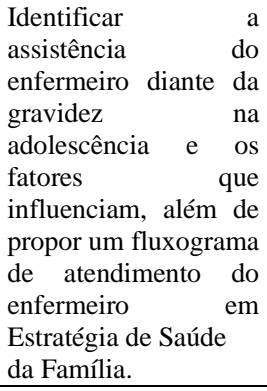 & $\begin{array}{l}\text { O enfermeiro deverá implementar ações } \\
\text { em consonância com as políticas públicas } \\
\text { e de maneira criativa e inovadora para que } \\
\text { promovam o vínculo, o diálogo e escuta } \\
\text { qualificados. É fundamental a capacitação } \\
\text { do enfermeiro para o acolhimento e } \\
\text { acompanhamento da gestação de uma } \\
\text { adolescente. }\end{array}$ \\
\hline 17 & SCIELO & $\begin{array}{l}\text { Rev Norte } \\
\text { Min } \\
\text { Enferm. }\end{array}$ & $\begin{array}{l}\text { Carvalho } \\
\text { et al., } \\
2012 .\end{array}$ & $\begin{array}{l}\text { Estudo de } \\
\text { campo, } \\
\text { descritivo, } \\
\text { qualitativo. }\end{array}$ & $\begin{array}{l}\text { Conhecimento dos } \\
\text { adolescentes de } \\
\text { escolas públicas } \\
\text { de Montes Claros } \\
\text { acerca do uso de } \\
\text { métodos contra- } \\
\text { ceptivos. }\end{array}$ & $\begin{array}{l}\text { Analisar o } \\
\text { conhecimento e o uso } \\
\text { de métodos } \\
\text { contraceptivos, bem } \\
\text { como identificar os } \\
\text { fatores associados ao } \\
\text { conhecimento ade- } \\
\text { quado desses méto- } \\
\text { dos entre adolescentes } \\
\text { de escolas públicas no } \\
\text { município de Montes } \\
\text { Claros-MG. }\end{array}$ & $\begin{array}{l}\text { Evidencia-se uma associação do pouco } \\
\text { conhecimento a variáveis } \\
\text { socioeconômicas. Isso sugere que os } \\
\text { jovens que possuem melhores condições } \\
\text { sociais têm acesso a informaçõ de } \\
\text { melhor qualidade, embora nem sempre } \\
\text { suficientes. Além disso, questões de } \\
\text { gênero e o início da vida sexual } \\
\text { influenciaram o nível de conhecimento, o } \\
\text { que provavelmente reflete a tradicional } \\
\text { ideia de que a anticoncepção é uma } \\
\text { atribuição feminina. Verifica-se, ainda, } \\
\text { que a iniciação sexual, principalmente em } \\
\text { idades mais tardias, motiva os } \\
\text { adolescentes à busca ativa de mais } \\
\text { informação a sobre métodos } \\
\text { anticoncepcionais. }\end{array}$ \\
\hline
\end{tabular}




\begin{tabular}{|c|c|c|c|c|c|c|c|}
\hline 18 & BDENF & $\begin{array}{l}\text { Revista } \\
\text { Científica } \\
\text { da Escola } \\
\text { da Saúde. }\end{array}$ & $\begin{array}{l}\text { Schmitz, } \\
\text { Secco, } \\
\text { Pinheiro, } \\
\quad \& \\
\text { Almeida, } \\
2013 \text {. }\end{array}$ & $\begin{array}{c}\text { Estudo } \\
\text { quantitativo. }\end{array}$ & $\begin{array}{lr}\text { Conhecimento } & \text { de } \\
\text { adolescentes } & \text { acer- } \\
\text { ca } & \text { da } \\
\text { contracepção } & \text { de } \\
\text { emergência. }\end{array}$ & 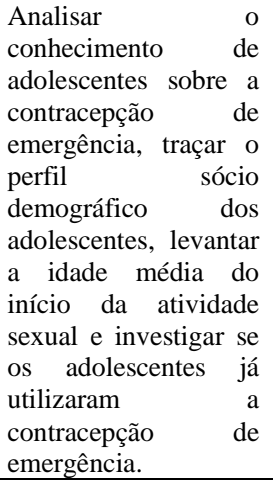 & $\begin{array}{l}\text { O uso da contracepção de emergência } \\
\text { entre os jovens é muito útil para alguns } \\
\text { casos, desde que corretamente, portanto, é } \\
\text { necessária uma ampliação dos } \\
\text { conhecimentos que os jovens possuem, } \\
\text { focalizando o uso correto, mecanismo de } \\
\text { ação, efeitos colaterais e os riscos } \\
\text { envolvidos. }\end{array}$ \\
\hline 19 & SCIELO & $\begin{array}{c}\text { Texto } \\
\text { Contexto } \\
\text { Enferm. }\end{array}$ & $\begin{array}{l}\text { Fiedler, } \\
\text { Araújo, } \\
\text { Souza, } \\
2014 .\end{array}$ & $\begin{array}{c}\text { Estudo } \\
\text { descritivo, } \\
\text { exploratório, } \\
\text { qualitativo. }\end{array}$ & $\begin{array}{ll}\text { A prevenção } & \text { da } \\
\text { gravidez } & \text { na } \\
\text { adolescência } & \text { na } \\
\text { visão } & \text { de } \\
\text { adolescentes. } & \end{array}$ & 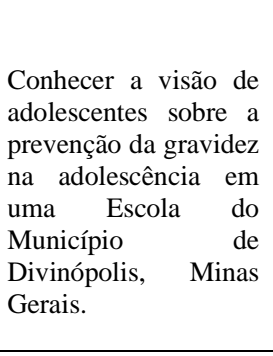 & $\begin{array}{l}\text { Evidencia-se que os adolescentes } \\
\text { consideram a prevenção da gravidez na } \\
\text { adolescência como algo positivo, } \\
\text { expressam seus conhecimentos sobre os } \\
\text { métodos contraceptivos, demonstram que } \\
\text { praticam sexo seguro e inseguro e } \\
\text { apontam falhas na qualidade da } \\
\text { assistência à saúde. Esforços do poder } \\
\text { público são necessários para a efetivação } \\
\text { das políticas públicas na atenção a saúde } \\
\text { dos adolescentes. }\end{array}$ \\
\hline 20 & SCIELO & $\begin{array}{l}\text { Brazilian } \\
\text { Journal Of } \\
\text { Health } \\
\text { Review. }\end{array}$ & $\begin{array}{l}\text { Almeida } \\
\text { et al., } \\
2021 .\end{array}$ & $\begin{array}{l}\text { Estudo } \\
\text { qualitativo }\end{array}$ & $\begin{array}{l}\text { As práticas } \\
\text { educativas seus } \\
\text { respectivos impac- } \\
\text { tos na prevenção } \\
\text { da gravidez na } \\
\text { adolescência. }\end{array}$ & $\begin{array}{l}\text { Descrever as práticas } \\
\text { educativas realizadas } \\
\text { pelo enfermeiro na } \\
\text { prevenção da gravidez } \\
\text { na adolescência. }\end{array}$ & $\begin{array}{l}\text { A enfermagem é uma área de grande } \\
\text { importância, suas ações e seus } \\
\text { profissionais possuem grande potencial } \\
\text { para contribuir significativamente para a } \\
\text { redução das estatísticas nos casos da } \\
\text { gravidez na adolescência. Ressalta-se } \\
\text { também, a relevância da interação entre a } \\
\text { educação e a saúde, afim de juntos, } \\
\text { encontrarem novas formas e ações para } \\
\text { interagir, orientar e lidar com o público } \\
\text { adolescente, de forma a reduzir os índices } \\
\text { de gravidez não planejada e abandono } \\
\text { escolar. }\end{array}$ \\
\hline 21 & SCIELO & $\begin{array}{l}\text { REME - } \\
\text { Rev Min } \\
\text { Enferm. }\end{array}$ & $\begin{array}{l}\text { Silva, } \\
\text { Nakagaw } \\
\text { a, Silva, } \\
\quad \& \\
\text { Espinosa, } \\
2019 .\end{array}$ & $\begin{array}{l}\text { Estudo do } \\
\text { tipo caso- } \\
\text { controle. }\end{array}$ & $\begin{array}{l}\text { Gravidez na } \\
\text { adolescência: uso } \\
\text { de métodos } \\
\text { anticonceptivos e } \\
\text { suas descontinui- } \\
\text { dades. }\end{array}$ & $\begin{array}{lr}\text { Analisar o } & \text { uso } \\
\text { MAC } & \text { por } \\
\text { adolescentes } & \text { que } \\
\text { engravidaram } & \text { nesse } \\
\text { período da vida. } & \end{array}$ & $\begin{array}{l}\text { Verifica-se que as adolescentes utilizam } \\
\text { menos métodos anticonceptivos, } \\
\text { comparado às jovens, desde o início da } \\
\text { vida sexual. Além disso, o uso é } \\
\text { permeado por descontinuidades, com } \\
\text { destaque para as falhas no uso do MAC. } \\
\text { Esse fato indica a necessidade de } \\
\text { aumentar os cuidados e opções } \\
\text { contraceptivas para essa população. }\end{array}$ \\
\hline 22 & SCIELO & $\begin{array}{c}\text { Editora } \\
\text { Científica. }\end{array}$ & $\begin{array}{l}\text { Pereira } e t \\
\text { al., } 2010 .\end{array}$ & $\begin{array}{c}\text { Estudo } \\
\text { transversal, } \\
\text { quantitativo. }\end{array}$ & $\begin{array}{l}\text { Conhecimento de } \\
\text { adolescentes sobre } \\
\text { métodos contra- } \\
\text { ceptivos. }\end{array}$ & 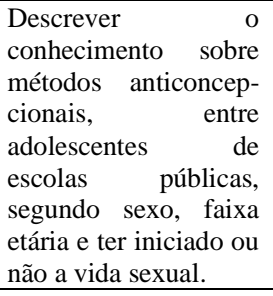 & $\begin{array}{l}\text { Apesar do conhecimento sobre os } \\
\text { anticoncepcionais ter aumentado é } \\
\text { necessária a formulação de ações } \\
\text { estratégicas que garantam a autonomia } \\
\text { reprodutiva de adolescentes em condições } \\
\text { desejadas e seguras. }\end{array}$ \\
\hline 23 & SCIELO & $\begin{array}{l}\text { Revista } \\
\text { Uningá } \\
\text { Review. }\end{array}$ & $\begin{array}{c}\text { Almeida, } \\
\text { Almeida, } \\
\text { Costa, \& } \\
\text { Firmo, } \\
2016 .\end{array}$ & $\begin{array}{l}\text { Estudo de } \\
\text { campo, } \\
\text { descritivo, } \\
\text { quantitativo. }\end{array}$ & $\begin{array}{l}\text { Conhecimento } \\
\text { sobre a } \\
\text { contracepção de } \\
\text { emergência por } \\
\text { adolescentes de } \\
\text { uma escola } \\
\text { pública de Lago } \\
\text { verde, Maranhão, } \\
\text { Brasil. }\end{array}$ & $\begin{array}{l}\text { Destacar a avaliação } \\
\text { do conhecimento } \\
\text { sobre a contracepção } \\
\text { de emergência por } \\
\text { adolescentes de uma } \\
\text { escola pública de } \\
\text { Lago Verde-MA. }\end{array}$ & $\begin{array}{l}\text { Apesar dos adolescentes terem } \\
\text { informações e conhecerem os métodos } \\
\text { contraceptivos, grande parte não usam os } \\
\text { métodos de maneira correta, facilitando a } \\
\text { ocorrência de uma gravidez inde sejada e } \\
\text { a disseminação das DST's. }\end{array}$ \\
\hline 24 & SCIELO & $\begin{array}{l}\text { Clin } \\
\text { Biomed } \\
\text { Res. }\end{array}$ & $\begin{array}{l}\text { Cardoso } \\
\text { et al., } \\
2019 .\end{array}$ & $\begin{array}{c}\text { Estudo } \\
\text { descritivo. }\end{array}$ & $\begin{array}{l}\text { A utilização de } \\
\text { contraceptivos } \\
\text { hormonais por } \\
\text { adolescentes e } \\
\text { potenciais riscos } \\
\text { para a saúde. }\end{array}$ & $\begin{array}{l}\text { Apresentar informa- } \\
\text { ções referentes } \text { aos } \\
\text { riscos do uso de } \\
\text { contraceptivos hor- } \\
\text { monais } \\
\text { adolescentes. }\end{array}$ & $\begin{array}{l}\text { Verifica-se que o uso de } \\
\text { anticoncepcionais hormonais é seguro e } \\
\text { bem tolerado pela população em geral. } \\
\text { Como qualquer terapêutica } \\
\text { medicamentosa, pode estar associada a } \\
\text { riscos. A indicação e utilização dos } \\
\text { mesmos por adolescentes apresentam, } \\
\text { como na população em geral, riscos e } \\
\text { benefícios evidenciados na literatura } \\
\text { internacional. }\end{array}$ \\
\hline
\end{tabular}




\begin{tabular}{|c|c|c|c|c|c|c|c|}
\hline 25 & LILACS & $\begin{array}{c}\text { Revista } \\
\text { Eletrônica } \\
\text { Acervo } \\
\text { Enfermage } \\
\text { m. }\end{array}$ & $\begin{array}{l}\text { Santana } \\
\text { et al., } \\
2021 .\end{array}$ & $\begin{array}{c}\text { Estudo } \\
\text { qualitativo. }\end{array}$ & $\begin{array}{lr}\text { Contracepção } & \text { re- } \\
\text { versível de longo } \\
\text { prazo } & \text { em } \\
\text { adolescentes: } & \text { be- } \\
\text { nefícios } & \text { e } \\
\text { barreiras. } & \end{array}$ & $\begin{array}{l}\text { Identificar } r \text { na } \\
\text { literatura científica as } \\
\text { evidências sobre os } \\
\text { fatores que interferem } \\
\text { na baixa escolha de } \\
\text { métodos } \quad \text { de } \\
\text { contracepção reversí- } \\
\text { vel de longo prazo } \\
\text { (LARCs) r em } \\
\text { adolescentes. }\end{array}$ & $\begin{array}{l}\text { Os maiores benefícios do uso de LARCs } \\
\text { em adolescentes é a baixa taxa de } \\
\text { descontinuidade do método e o fato de } \\
\text { não depender da usuária para ser eficaz, } \\
\text { como no caso dos métodos de } \\
\text { contracepção de curta duração, onde } \\
\text { alguns exigem um esforço diário que } \\
\text { muitas adolescentes não conseguem } \\
\text { manter, o que acaba resultando em uma } \\
\text { gestação não planejada. }\end{array}$ \\
\hline 26 & BDENF & $\begin{array}{l}\text { Rev Bras } \\
\text { Promoç } \\
\text { Saúde. }\end{array}$ & $\begin{array}{c}\text { Queiroz, } \\
\text { Alcântara } \\
\text {, Brasil, } \\
\text { \& Silva, } \\
2016 .\end{array}$ & $\begin{array}{c}\text { Estudo } \\
\text { descritivo. }\end{array}$ & $\begin{array}{l}\text { Participação de } \\
\text { adolescentes em } \\
\text { ações educativas } \\
\text { sobre saúde sexual } \\
\text { e contracepção. }\end{array}$ & $\begin{array}{lr}\text { Descrever } & \text { a } \\
\text { participação de } \\
\text { adolescentes em ações } \\
\text { educativas sobre } \\
\text { saúde sexual e } \\
\text { contracepção. }\end{array}$ & $\begin{array}{l}\text { Observa-se que o conhecimento adquirido } \\
\text { pelos adolescentes nesta temática, advém } \\
\text { de interações sociais, principalmente com } \\
\text { os pares e denotam falta de conversas } \\
\text { mais direcionadas sobre os meios de } \\
\text { prevenção, seja com os pais, nas escolas } \\
\text { ou nas unidades de saúde. Apesar de os } \\
\text { adolescentes conhecerem os métodos } \\
\text { contraceptivos, comumente utilizados por } \\
\text { eles, não há segurança e confiabilidade } \\
\text { em relação ao uso do preservativo } \\
\text { masculino, como também na } \\
\text { anticoncepção de emergência, } \\
\text { anticoncepcional oral e injetável, uma vez } \\
\text { que suas afirmações mostravam esta } \\
\text { realidade. }\end{array}$ \\
\hline 27 & SCIELO & $\begin{array}{c}\text { Revista de } \\
\text { Divulgação } \\
\text { Científica } \\
\text { Sena Aires. }\end{array}$ & $\begin{array}{c}\text { Valverde, } \\
\& \\
\text { Oliveira, } \\
2014 .\end{array}$ & $\begin{array}{c}\text { Estudo } \\
\text { qualitativo. }\end{array}$ & $\begin{array}{lr}\text { Adolescentes } & \text { e } \\
\text { jovens e } & \text { a } \\
\text { contracepção } & \text { de } \\
\text { emergência. } & \end{array}$ & $\begin{array}{l}\text { Identificar } \\
\text { conhecimento cientí- } \\
\text { fico produzido entre } \\
\text { agosto de } 2013 \text { e } \\
\text { outubro de } 2013 \text { sobre } \\
\text { o uso da contracepção } \\
\text { de emergência por } \\
\text { adolescentes e jovens. }\end{array}$ & $\begin{array}{l}\text { O conhecimento sobre métodos } \mathrm{e} \\
\text { sexualidade, contribui para a melhor } \\
\text { escolha da anticoncepção. O } \\
\text { conhecimento entre adolescentes e jovens } \\
\text { é consideravelmente alto, mas, sua } \\
\text { formade uso e as escolhas que a levam a } \\
\text { utiliza-las é preocupante, pois existem } \\
\text { meios e métodos anticoncepcionais mais } \\
\text { eficazes, proporcionando uma proteção e } \\
\text { confiabildade melhor. Dessa forma, } \\
\text { destaca-se a importância do acesso a } \\
\text { informação de qualidade em relação à AE, } \\
\text { para que as adolescentes e jovens, as } \\
\text { utilizem quando necessário e de forma } \\
\text { adequada, sem o abandono do método } \\
\text { regular e, principalmente, sem deixar de } \\
\text { utilizar o preservativo, pois se trata do } \\
\text { único método eficaz na prevenção de } \\
\text { DST's e AIDS. }\end{array}$ \\
\hline
\end{tabular}

Fonte: Autores (2021).

No Quadro 1, tem-se a apresentação dos artigos selecionados para o estudo conforme número do artigo, base de dados, periódico, autor e ano de publicação, tipo de estudo, título, objetivo, resultados em evidências e conclusões importantes, com a finalidade de facilitar o desenvolvimento da discussão. A partir do estudo dos artigos estabeleceram-se discussões relevantes para observações das produções científicas relacionadas à pesquisa.

No gráfico a seguir, estão expostos os periódicos e a quantidade de artigos encontrados na seleção da amostra final dos artigos que são trabalhados na elaboração do referido estudo. 
Gráfico 1. Distribuição dos artigos conforme periódico e quantidade e quantidade de artigos.

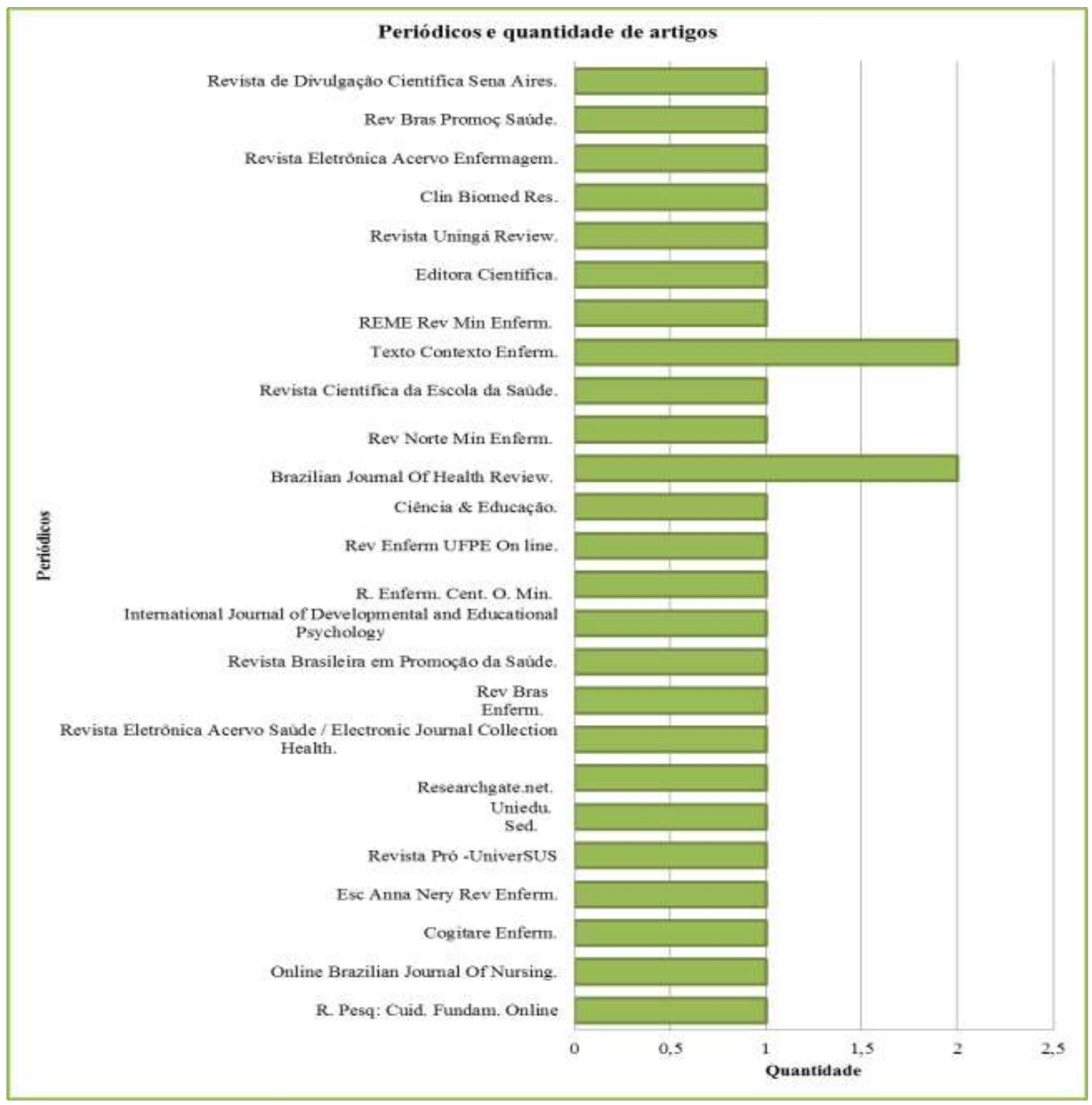

Fonte: Autores (2021).

Segundo o gráfico ilustrado acima, pode-se observar os periódicos e a quantidade de artigos que foram publicados de acordo com a amostra final do referido estudo. Dessa forma, verifica-se que na Revista de Divulgação Científica Sena Aires Ocorreu (1) publicação, Revista Brasileira Promoção da Saúde (1), Revista Eletrônica Acervo Enfermagem (1), Clin Biomed Res (1) Revista Uningá Review (1), Editora Científica (1), REME - Revista Mineira de Enfermagem (1), Texto Contexto Enfermagem (1), Revista Científica da Escola da Saúde (1), Rev Norte Min Enferm (1), Brazilian Journal Of Helth Review (2), Ciência Educação (1), Revista Enferm UFPE Online (1), R Enferm Cent O Min (1), International Journal Of Developmental and Educational Psychology (1), Revista Brasileira em Promoção da Saúde (1), Revista Brasileira de Enfermagem (1), Revista Eletrônica Acervo saúde (1), Researchgate Net (1), Uni Edu Sed (1), Revista Pró-UniverSUS (1), Esc Anna Nery Rev Enferm (1), Cogitare Enferm (2), Online Brazilian Journal Of Nursing (1), R Pesquisa Cuid Fundam Online (1). Assim, totalizando 27 artigos para serem trabalhados na elaboração do presente estudo. 
Gráfico 2. Distribuição dos artigos conforme periódicos e porcentagem.

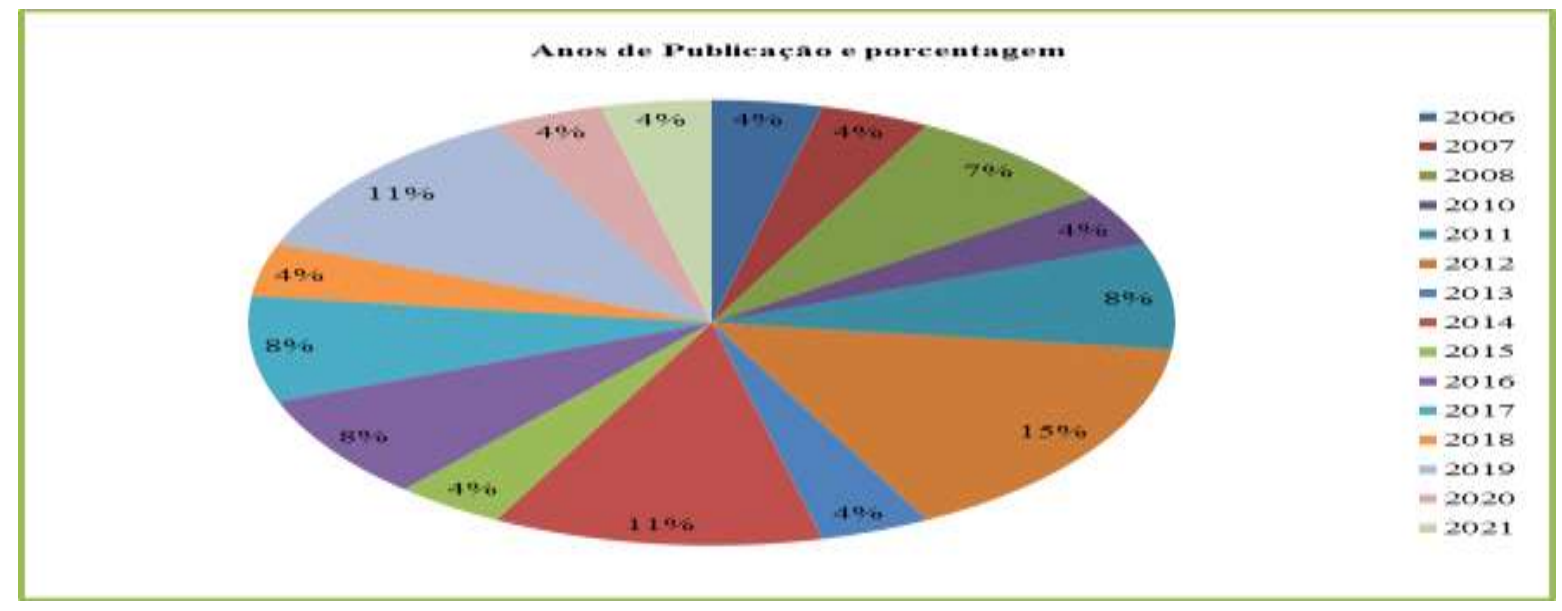

Fonte: Autores (2021).

De acordo, com o gráfico ilustrado acima, pode-se observar os periódicos e a porcentagem de artigos que foram publicados de acordo com a amostra final do referente estudo. Dessa forma, verifica-se que na Revista de Divulgação Científica Sena Aires Ocorreu (4\%) publicação, Revista Brasileira Promoção da Saúde (4\%), Revista Eletrônica Acervo Enfermagem (4\%), Clin Biomed Res (4\%) Revista Uningá Review (4\%), Editora Científica (4\%), REME - Revista Mineira de Enfermagem (4\%), Texto Contexto Enfermagem (4\%), Revista Científica da Escola da Saúde (4\%), Rev Norte Min Enferm (4\%), Brazilian Journal Of Helth Review (7\%), Ciência Educação (4\%), Revista Enferm UFPE Online (4\%), R Enferm Cent O Min (4\%), International Journal Of Developmental and Educational Psychology (4\%), Revista Brasileira em Promoção da Saúde (4\%), Revista Brasileira de Enfermagem (4\%), Revista Eletrônica Acervo saúde (4\%), Researchgate Net (4\%), Uni Edu Sed (4\%), Revista Pró-UniverSUS (4\%), Esc Anna Nery Rev Enferm (4\%), Cogitare Enferm (7\%), Online Brazilian Journal Of Nursing (4\%), R Pesquisa Cuid Fundam Online (4\%). Assim, totalizando 27 artigos para serem trabalhados na elaboração do presente estudo.

Gráfico 3. Distribuição dos artigos conforme os anos de publicação e quantidade.

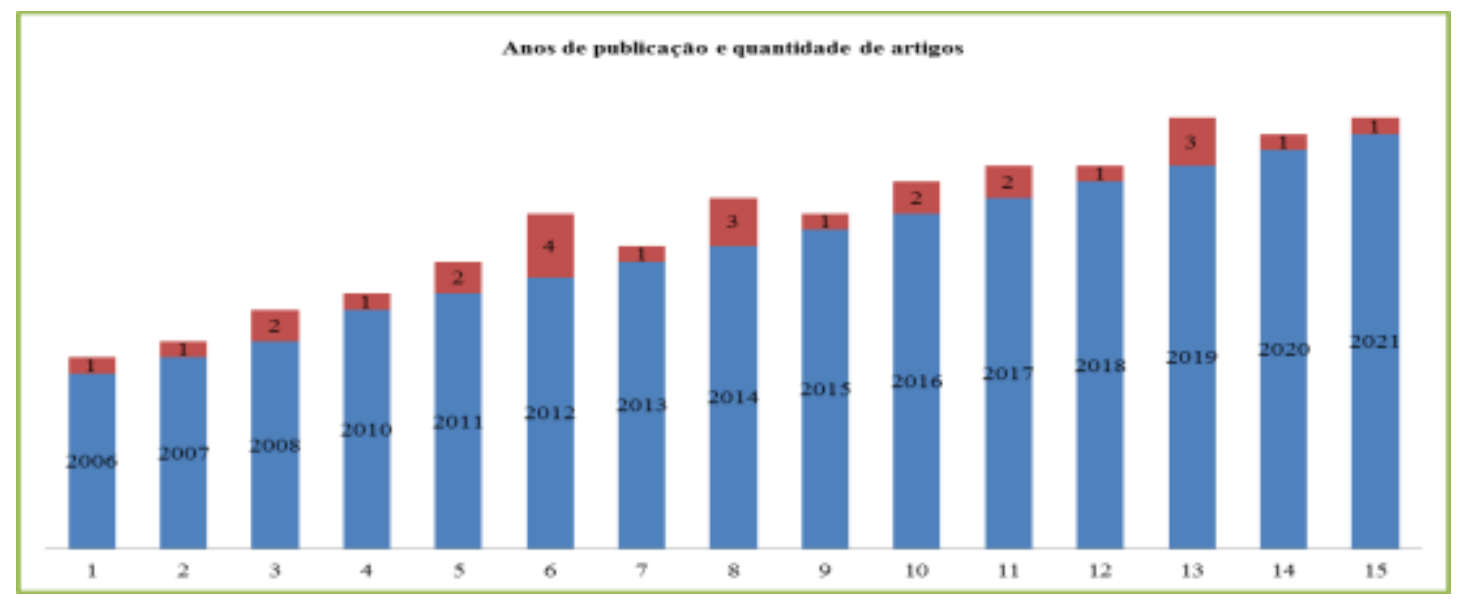

Fonte: Autores (2021).

Ao analisar o gráfico representado acima, observa-se os anos de publicação e a quantidade de artigos publicados, nota-se que no ano de 2006 (1) publicação, 2007 (1), 2008 (2), 2010 (1), 2011 (2), 2012 (4), 2013 (1), 2014 (3), 2015 (1), 2016 (2), 2017 (2), 2018 (1), 2019 (3), 2020 (1), 2021 (1). Assim, totalizando 27 artigos publicados e selecionados para serem utilizados na elaboração do presente estudo. 
Research, Society and Development, v. 10, n. 11, e437101119575, 2021

(CC BY 4.0) | ISSN 2525-3409 | DOI: http://dx.doi.org/10.33448/rsd-v10i11.19575

Gráfico 4. Distribuição dos anos de publicação e porcetagem.

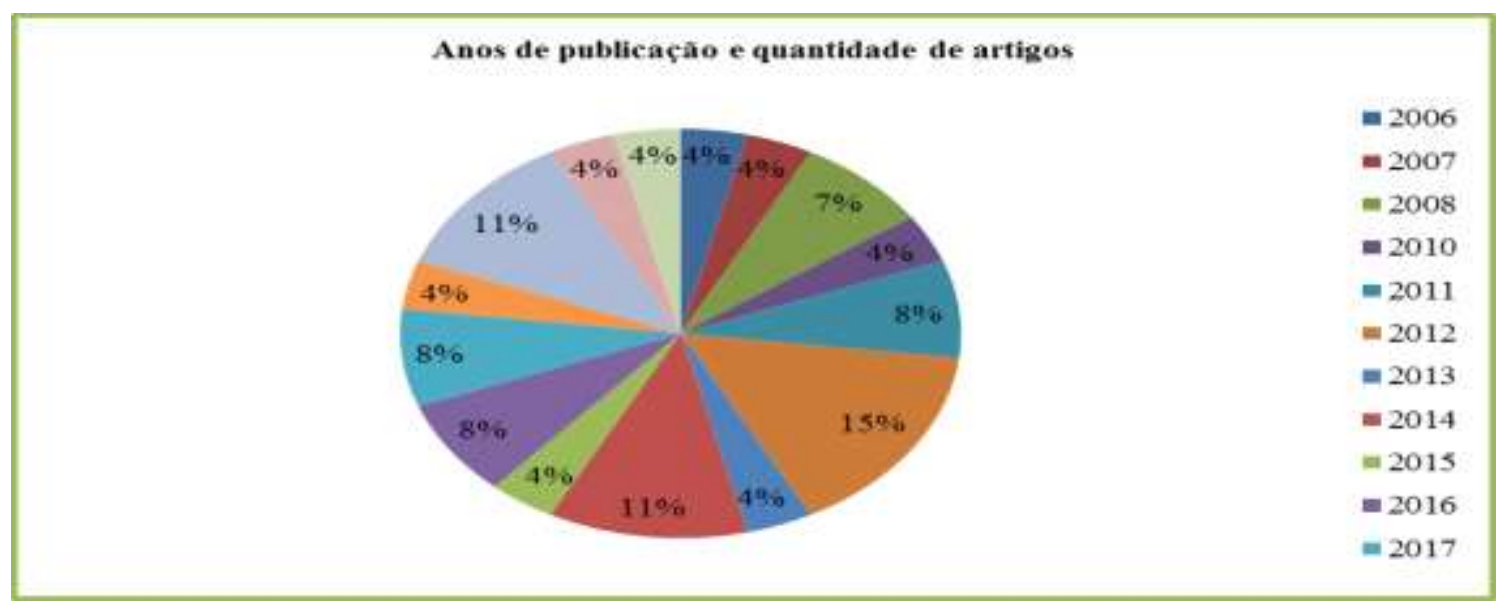

Fonte: Autores (2021).

Ao verificar o gráfico acima, percebe-se os anos de publicação e porcentagem dos artigos publicados de acordo com cada ano, identifica-se que no ano de 2006 (4\%) publicação, 2007 (4\%), 2008 (7\%), 2010 (4\%), 2011 (8\%), 2012 (15\%), 2013 (4\%), 2014 (11\%), 2015 (4\%), 2016 (8\%), 2017 (8\%), 2018 (4\%), 2019 (11\%), 2020 (4\%), 2021 (4\%). Totalizando 100\% das publicações, escolhidas para compor a construção do referido estudo.

Gráfico 5. Distribuição dos artigos conforme os tipos de estudo e quantidade.

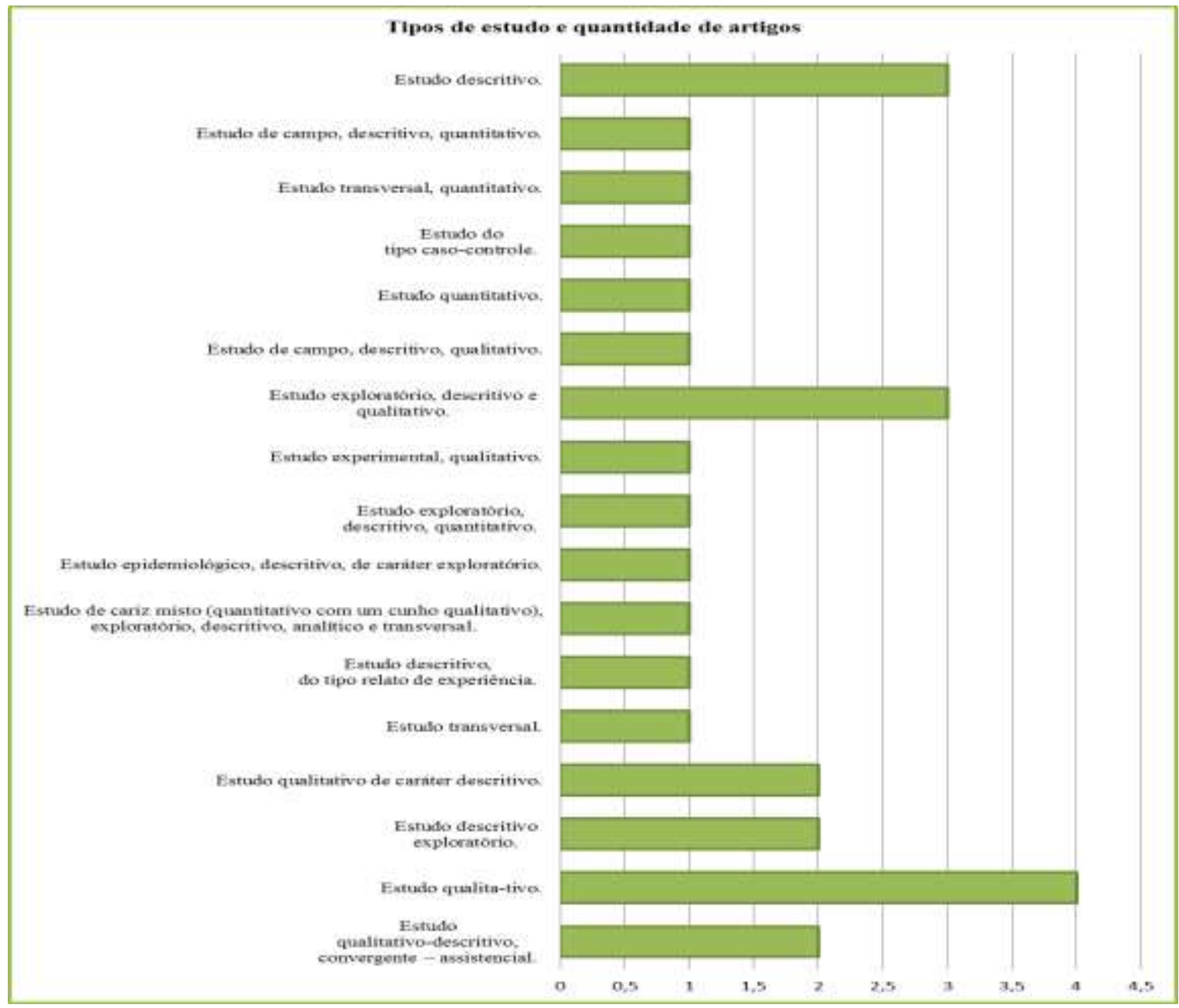

Fonte: Autores (2021). 
Ao analisar o gráfico representado acima, identificam-se os tipos de estudo e a quantidade de artigos publicados. Nota-se que, evidenciou-se um total de: estudo descritivo (3), estudo de campo, descritivo, quantitativo (1), estudo transversal, quantitativo (1), estudo do tipo caso-controle (1), estudo quantitativo (1), estudo de campo, descritivo, qualitativo (1), estudo exploratório, descritivo e qualitativo (3), estudo experimental qualitativo (1), estudo exploratório, descritivo, quantitativo (1), estudo epidemiológico, descritivo, caráter exploratório, estudo experimental qualitativo (1), estudo de cariz misto (qualitativo com o cunho quantitativo (1), exploratório, descritivo, analítico, e transversal (1), estudo descritivo, do tipo relato de experiênci (1), estudo transversal (1), estudo qualitativo com caráter descritivo (1), estudo descritivo exploratório (2), estudo qualitativo (4), estudo qualitativo descritivo, convergente assistencial (2). Totalizando 27 estudos selecionados na amostra final para construção do presente estudo.

Gráfico 6. Distribuição dos artigos conforme tipos de estudo e porcentagens.

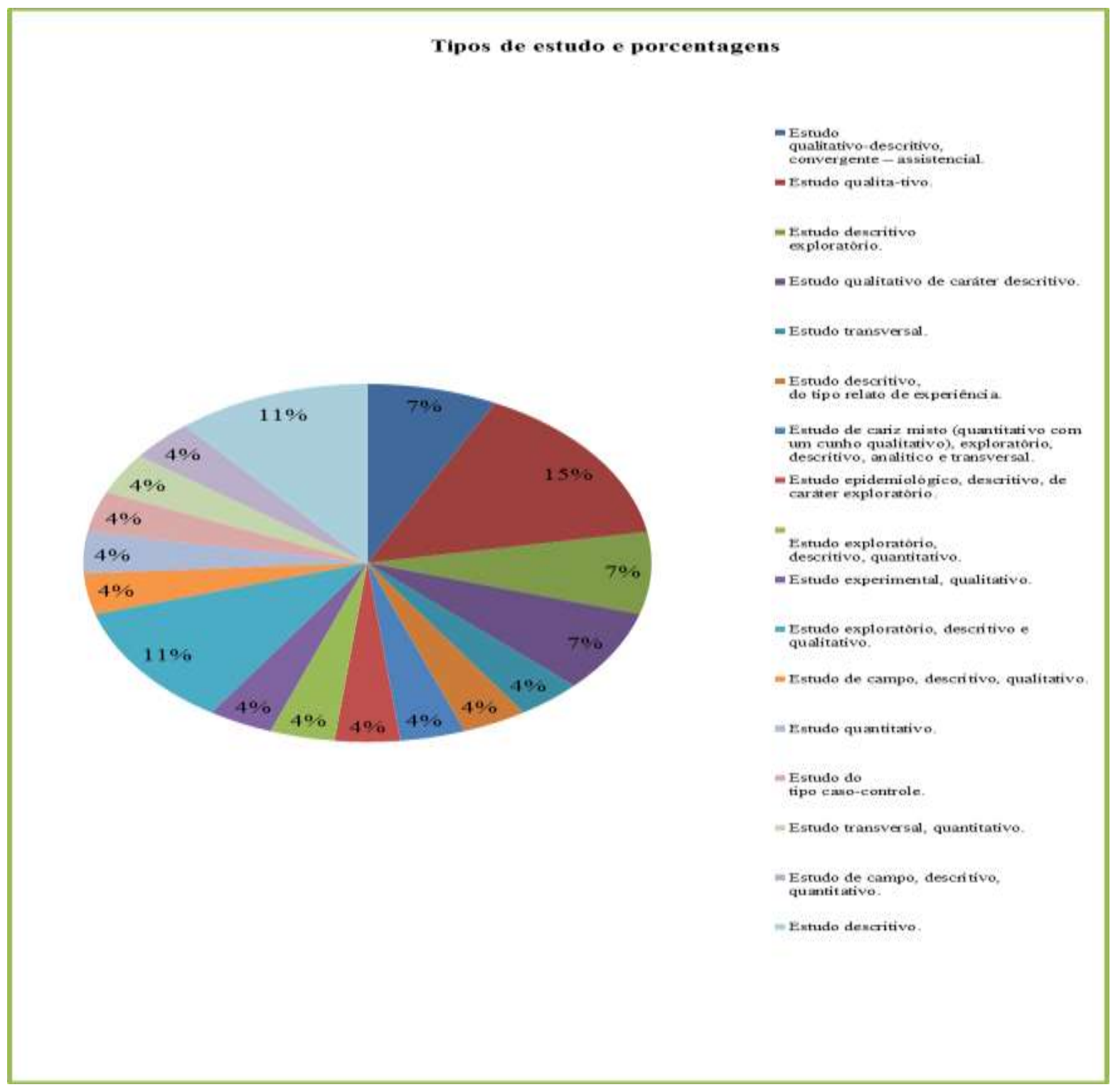

Fonte: Autores (2021).

Ao analisar o gráfico ilustrado acima percebe-se os tipos de estudos e a porcentagens de artigos selecionados para elaboração do presente estudo. Assim, nota-se que estudo descritivo (11\%), estudo de campo, descritivo, quantitativo (4\%), estudo transversal, quantitativo (4\%), estudo do tipo caso-controle (4\%), estudo quantitativo (4\%), estudo de campo, 
descritivo, qualitativo (4\%), estudo exploratório, descritivo e qualitativo (11\%), estudo experimental qualitativo (4\%), estudo exploratório, descritivo, quantitativo (4\%), estudo epidemiológico, descritivo, caráter exploratório, estudo experimental qualitativo (4\%), estudo de cariz misto - qualitativo com o cunho quantitativo (4\%), exploratório, descritivo, analítico, e transversal (4\%), estudo descritivo, do tipo relato de experiência (4\%), estudo transversal (4\%), estudo qualitativo com caráter descritivo (7\%), estudo descritivo exploratório (7\%), estudo qualitativo (15\%), estudo qualitativo descritivo, convergente assistencial (7\%).

Gráfico 7. Distribuição dos artigos de acordo com as bases de dados e a quantidade de artigos.

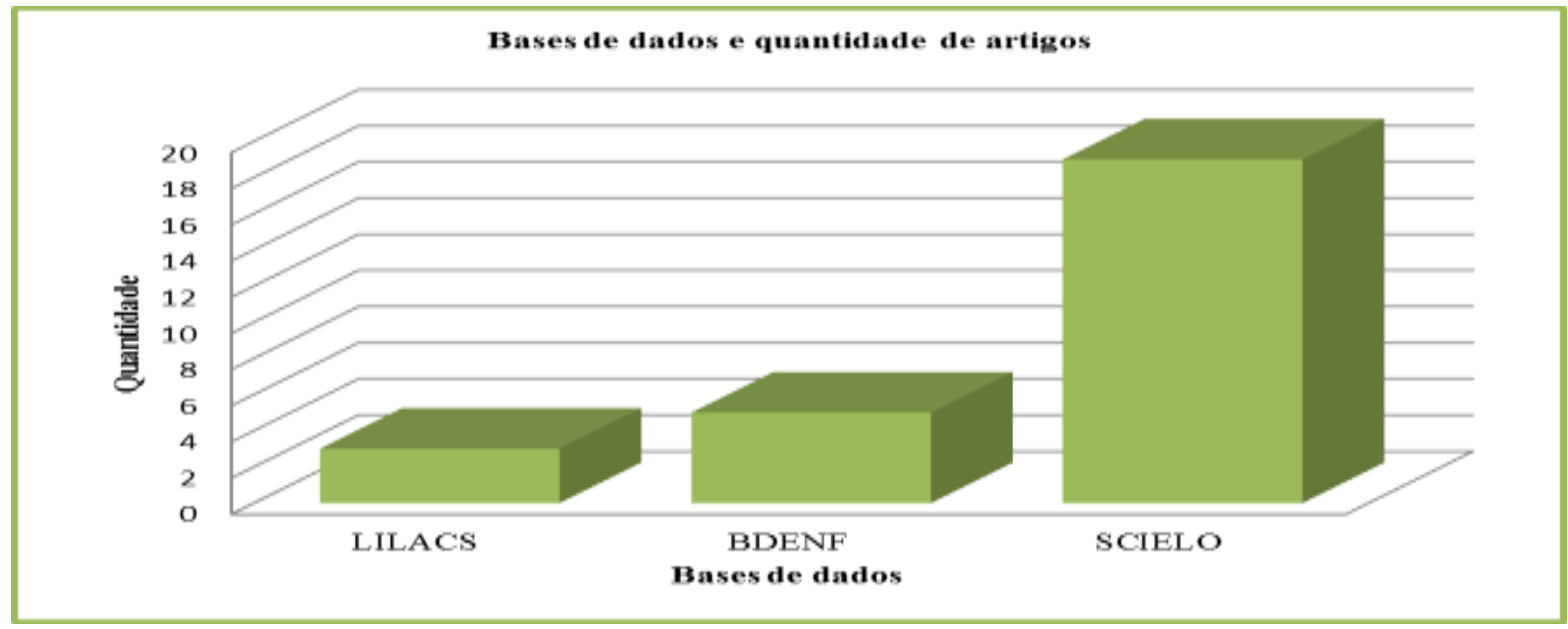

Fonte: Autores (2021).

Segundo o gráfico representado acima é possível identificar as bases de dados e a quantidade de artigo publicados em cada uma. Nota - se que na Literatura Latino-Americana e do Caribe em Ciências da Saúde (LILACS) ocorreu (3) publicações, Base de Dados de Enfermagem (BDENF), (5) e - Scientific Electronic Library Online (SCIELO) (19). Sendo que foram adotados os critérios metodológicos na elaboração do referido estudo.

Gráfico 8. Distribuição dos artigos de acordo com as bases de dados e a porcentagem.

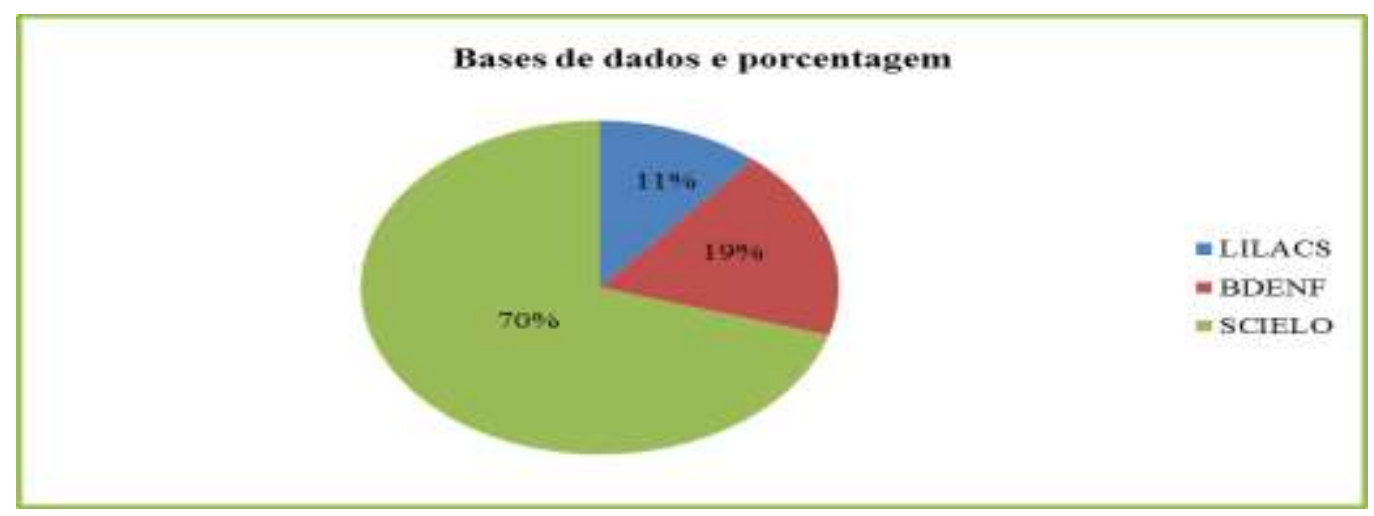

Fonte: Autores (2021).

De acordo com o gráfico ilustrado acima identifica-se as bases de dados e a porcentagem dos artigo publicados em cada uma. Nota - se que na Literatura Latino-Americana e do Caribe em Ciências da Saúde (LILACS) ocorreu (11\%) das publicações, Base de Dados de Enfermagem (BDENF), (19\%) e - Scientific Electronic Library Online (SCIELO) (70\%). Sendo que foram adotados os critérios metodológicos na elaboração do presente estudo. 
A adolescência é o período em que ocorre a transição da passagem da infância para a vida adulta. Neste período ocorrem transformações biológicas, psicológicas e sociais relacionadas ao crescimento físico, maturação sexual e aquisição da capacidade de reprodução, que permitem o desenvolvimento de uma identidade adulta. A adolescência é nomeada como uma etapa onde valores influenciam as decisões e o comportamento do jovem, estes valores são conhecidos por eles por meio da família, comunidade e cultura dos quais estão inseridos (Kempfer, Fraga, Mafra, Hoffman, \& Lazzari, 2012).

A adolescência é um momento decisivo no desenvolvimento sexual humano, pois é nela que a sexualidade se generaliza, ocorrendo intensas transformações biopsicossociais. A descoberta do prazer, muitas vezes, dá-se nessa época, onde por sua vez a sexualidade precoce aumenta a vulnerabilidade às Infecções Sexualmente Transmissíveis (IST), inclusive a contaminação pelo Vírus da Imunodeficiência Adquirida (HIV) e o desenvolvimento da Síndrome da Imunodeficiência Adquirida (AIDS), a gravidez na adolescência de forma não planejada e outros riscos, o que interfere em suas metas de vida futura (Pereira et al., 2019).

A vivência da sexualidade, nesse período, torna-se mais evidente e em geral manifesta-se através de práticas sexuais desprotegidas, devido à falta de informação, de comunicação entre familiares e de alguns mitos, tabus, ou mesmo pelo fato de ter medo de assumir sua própria sexualidade. Dessa forma, a procura e a curiosidade por novas experiências e a falta de orientações sobre as mudanças pelas quais estão passando tornam os adolescentes vulneráveis a situações de risco, dentre as quais as Infecções Sexualmente Transmissíveis (IST), incluindo a Síndrome da Imunodeficiência Adquirida (AIDS) (Almeida et al., 2017).

A saúde dos adolescentes brasileiros merece a atenção dos profissionais da enfermagem no que diz respeito à proteção, prevenção e recuperação da saúde, sendo necessário o estabelecimento de estratégias que atendam essa população de forma humanizada, personalizada e, evidentemente, com qualidade nos serviços. A gravidez na adolescência causa grande impacto familiar, a partir do momento de sua descoberta, já que a família constitui o primeiro grupo de referência para os adolescentes e é vista como espaço para aprendizagem da socialização e dos valores a serem seguidos pelo grupo. Além disso, a gravidez não planejada, pode revelar-se em um grave problema para a saúde sexual e saúde reprodutiva de adolescentes e jovens brasileiros, como atesta o número de atendimentos decorrentes de aborto no SUS, bem como nos índices de óbitos maternos juvenis (Kempfer, Fraga, Mafra, Hoffman, \& Lazzari, 2012).

Segundo Rodriguês e Jardim (2012), ressaltam o papel do enfermeiro como educador em saúde atuando em unidades básicas de saúde, entre outros espaços sociais, como a escola, devidamente capacitados para a função educativa, auxiliando o adolescente no processo de construção do conhecimento e sua utilização para o autocuidado.

A atuação do enfermeiro, como de toda a equipe de saúde, tem as ações centradas na tríade promoção, prevenção e assistência, sendo as duas primeiras de maior relevância no processo de trabalho que vai ao encontro dos princípios e diretrizes do Sistema Único de Saúde. As ações de promoção da saúde são consideradas de grande relevância, para corresponsabilidade e fortalecimento do vínculo na relação enfermeiro adolescente. A promoção da saúde permeia transversalmente todas as políticas, programas e ações da saúde, com o desafio de constituir a integralidade e equidade (Gurgel, Alves, Vieira, Pinheiro, \& Barroso, 2018).

A gravidez na adolescência decorre, principalmente, da não-utilização de método contraceptivo e, em menor porcentagem, da utilização inadequada desses métodos. Nessas circunstâncias, as ações de prevenção assumem papel de suma importância, devendo incluir não apenas a oferta de preservativos feminino e masculino e os demais métodos anticoncepcionais, mas também a garantia de espaço para que o adolescente possa falar de si próprio, trocar experiência e receber informações que favoreçam a adoção de hábitos saudáveis de vida. Estudo realizado na América Latina demonstrou que menos de $20 \%$ dos homens e de $15 \%$ das mulheres usavam algum método anticoncepcional na primeira relação. A prevenção da gravidez na adolescência é uma coresponsabilidade de cada componente da equipe da saúde e vai além de 
aprimorar a escuta, fortalecer os vínculos, garantir o acesso às informações e aos métodos anticoncepcionais. São de indescartável relevância a intersetorialidade e as ações coletivas para a promoção e desenvolvimento de atitudes e habilidades nos adolescentes para lidar com a sexualidade, aumentando o seu poder de decisão para não ceder às pressões, ampliar a força de negociação, desenvolver o autocuidado, ampliar o acesso a atividades educativas e recreativas e estimular o protagonismo. (Gurgel, Alves, Vieira, Pinheiro, \& Barroso, 2018).

Constata-se que a gravidez na adolescência é um problema de saúde pública que pode gerar repercussões significativas. É de vital importância a prática educativa nesse processo salientando a integração com os profissionais no ambiente do cuidado. Isto possibilita a troca de experiências entre os próprios adolescentes juntamente com enfermeiros educadores em saúde. Portanto, o profissional enfermeiro é habilitado e capacitado para prestar cuidado ao cliente e sua família em todas suas esferas existenciais, considerando as necessidades curativas, preventivas e educativas de cuidados em saúde (Ribeiro et al., 2017).

O enfermeiro ministra o cuidado ao sujeito, que é o ser humano em todo o seu ciclo vital. Atuando nas inúmeras situações relacionadas ao processo saúde-doença desempenhando papéis nos diversos campos de atenção. Portanto cabe a este profissional tratar questões que englobem o adolescente e o processo de desenvolvimento na adolescência. Neste contexto a prática educativa em saúde mostra-se relevante, baseando-se no momento singular que vivemos, onde há democratização no acesso as informações sendo que a globalização tem como característica tornar amplo o conhecimento a medidas contraceptivas. Assim, é necessário que haja a mudança de entendimento do adolescente sobre o planejamento reprodutivo, para isto é necessário que este serviço não se configure apenas em medidas para evitar a gravidez, mas numa forma de aprendizado sobre sua sexualidade, sendo de extrema relevância principalmente para a tomada de decisão do início ou não da atividade sexual. A escola é o espaço ideal pra que haja essa mudança de pensamento, já que tal ação poderia ocorrer de forma gradativa (Ribeiro et al., 2017).

O conhecimento é de extrema importância, mas viver e ter relações sexuais sem que haja uma gravidez como consequência, ou até mesmo a transmissão de alguma doença sexualmente transmissível é um dos principais desafios desta geração de adolescentes brasileiros. Obter informações consistentes e seguras sobre sexualidade e contracepção é um novo caminho a ser percorrido, onde existem riscos e encruzilhadas decisivas, e onde o profissional de saúde que lida com os adolescentes pode exercer o papel de bússola, permitindo uma melhor orientação para a prevenção da gravidez. A escolha do método contraceptivo mais adequado deveria reunir quesitos fundamentais como: ser de fácil aplicação, possuir 100\% de eficácia, risco zero e ausência total de efeitos colaterais, porém diferente do que é a realidade atual, sabe-se que não existe nenhum método que reúna todas essas qualidades. Os profissionais de saúde que trabalham com adolescentes devem possuir conhecimentos sobre os diversos métodos disponíveis e saber quais os mais utilizados nessa faixa etária. Esses métodos podem ser divididos em comportamentais, de barreira, hormonais, dispositivos intra-uterinos e cirúrgicos (Varela, \& Borges, 2015).

O desenvolvimento tecnológico no campo da contracepção e os avanços no âmbito da saúde sexual e reprodutiva disponibilizam informações e meios relacionados aos métodos contraceptivos. Oferecer opções de escolha à jovem, ou até mesmo ao casal, gera segurança e, consequentemente, melhor utilização do método. Implica em uma vida sexual segura e satisfatória, tendo a capacidade de reproduzir e a liberdade de decidir sobre quando e quantas vezes deve fazê-lo. Os aspectos destacados denotam a vulnerabilidade a que está exposto este público alvo e, certamente, reforçam a necessidade de um olhar voltado para esta clientela no sentido de minimizar os agravos decorrentes, quer seja de ausência de políticas públicas ou de estratégias que possibilitem os adolescentes mudarem de comportamento para a promoção de sua saúde (Timbó et al., 2020).

A ocorrência de gravidez não planejada constitui um indicador de falha na saúde reprodutiva, que pode ser decorrente de múltiplos fatores, como sexo sem proteção, uso incorreto e descontínuo dos métodos contraceptivos, dificuldades na negociação com o parceiro para o uso do preservativo, além do acesso precário à informação e aos métodos contraceptivos. O 
desconhecimento dos métodos contraceptivos ou a sua utilização incorreta constituem fatores relacionados à ocorrência de gestação entre adolescentes. Porém, estudos apontam que as adolescentes conhecem pelo menos um método contraceptivo e sabem onde ter acesso a ele, embora isso não seja garantia de que irá utilizá-lo de forma segura e eficaz. Ao analisar todos esses fatores, é perceptível que ainda existem dificuldades para o adolescente pôr em prática a utilização das medidas contraceptivas, apesar de muitas vezes possuir conhecimento. A despeito de constituir elemento-chave, a informação não é suficiente para o uso dos anticoncepcionais pelos adolescentes, não havendo tradução do conhecimento em práticas seguras (Araújo, \& Nery, 2018).

O conhecimento não é o único fator responsável, mas contribui significativamente para o desfecho da gravidez não planejada, pois o fato de a adolescente não saber utilizar a pílula do dia seguinte aumenta em 3,93 vezes a chance de ter uma gravidez não planejada. Porém, outros fatores, como idade, sexo, renda, estado civil e escolaridade estão também associados à gravidez na adolescência e ao não planejamento da gestação. Portanto, é fundamental uma assistência direcionada a esse público, considerando suas singularidades e a necessidade de prevenção dos agravos. As equipes de atenção básica não podem esquivar-se mediante as dificuldades encontradas no trabalho com adolescentes, pois também são responsáveis por esse processo, e o profissional enfermeiro deve constituir um elo entre o adolescente e a UBS, com auxílio das escolas e famílias. Seguindo esse ponto de vista, a atuação do enfermeiro, dentro da atenção básica e em programas como saúde na escola, pode contribuir para levar esclarecimentos e conhecimento a esse grupo, pois o enfermeiro na saúde pública não deixa de ter também o papel de educador e formador de opiniões (Araújo, \& Nery, 2018).

Neste contexto, as ações de educação em saúde abordando temas como sexualidade, métodos contraceptivos e as IST's, HIV e AIDS são consideradas como ferramenta importante na promoção da saúde e prevenção de doenças. É necessário construir um conhecimento crítico dos adolescentes em relação a sua saúde, favorecendo a eles o empoderamento de cuidar de si próprio, os responsabilizando de manter sua saúde e se prevenir contra as IST's e uma gravidez indesejada. O conhecimento adequado sobre os diversos métodos contraceptivos disponíveis pelos jovens é de grande importância para que seja feita a melhor escolha, adequando-a as condições socioeconômicas, comportamento sexual, além de auxiliar o uso correto (Pereira et al., 2019).

A assistência ao planejamento familiar orienta-se por ações preventivas e educativas, pela garantia do acesso igualitário às informações, métodos e técnicas disponíveis para regulação da fecundidade, devendo atender às reais necessidades da população feminina e masculina em idade fértil, através da utilização dos conhecimentos técnicos-científico existentes e dos meios e recursos mais adequados e disponíveis. Contudo, a baixa qualidade da assistência em planejamento familiar reflete no aumento da fecundidade na adolescência, bem como em grande número de abortos que ocorrem no Brasil, dos quais uma significativa proporção é induzida e contribui para altas taxas de mortalidade materna (Bié, Diógenes, \& Moura, 2006).

Os profissionais de enfermagem dos cuidados de saúde primários estão numa posição chave, no sentido de promover hábitos sexuais saudáveis, contribuindo para a melhoria do nível de saúde dos adolescentes. São vários os estudos e diversos os autores estudiosos da temática em apreço, que têm demonstrado que muitos adolescentes, apesar de referirem possuir conhecimentos sobre sexualidade e métodos contraceptivos, não os materializam, com todas as consequências óbvias que isso imputa. Pelo exposto, torna-se imperativo que se criem estratégias de prevenção, que visem uma prática sexual consciente e responsável, potencializando estilos de visa saudáveis, diminuindo a incidência de problemas que daí possa resultar. Os problemas e dificuldades existem, não podem e não devem ser escamoteados, devem ser falados, debatidos e estudados, de forma a permitir e facilitar uma melhor compreensão sobre esta etapa. Contribuindo para que a sexualidade possa ser vivenciada da forma mais saudável. A sexualidade teima em ser ainda, tema de difícil abordagem, pois persistem a existência 
de fatores condicionantes e inibidores da expressão dos pensamentos, atitudes e das próprias práticas (Brás, Anes, Praça, \& Morais, 2011).

A escolha do método contraceptivo deve ser responsabilidade do casal. Nesse sentido ressalta-se a importância da assistência integral a saúde sexual e reprodutiva de homens e mulheres, com implantação de programas que incluam a reflexão acerca da dinâmica das relações e dos papéis sociais. A falta de informação e de acesso aos métodos contraceptivos, os mitos, a insegurança, a falta de instrução e o desajuste familiar são alguns dos fatores que contribuem para o aumento da gravidez não planejada entre os adolescentes e jovens. Os adolescentes falham em utilizar os contraceptivos por uma série de razões, entre as quais: a falta de consciência que a gestação pode acontecer com intercurso, à falta de conhecimento sobre a disponibilidade dos contraceptivos, a objeção do parceiro quanto ao uso, o medo de perder o parceiro, o intercurso não planejado, a indisponibilidade do contraceptivo no momento do intercurso, a percepção de que a contracepção é um problema da mulher e o entendimento que o parceiro cuidará disto (Santos, Rodrigues, Araújo, Vasconcelos, 2007).

$\mathrm{O}$ acesso à informação de boa qualidade e a disponibilidade de alternativas contraceptivas são aspectos fundamentais nos programas de planejamento familiares destinados não apenas aos adolescentes, mas à população em geral. $\mathrm{O}$ conhecimento inadequado sobre qualquer MAC pode ser um fator de resistência à aceitabilidade e uso desse método. Do mesmo modo, alto nível de conhecimento sobre MAC não determinará nenhuma mudança de comportamento se os métodos contraceptivos não estiverem acessíveis à livre escolha dos adolescentes. Atualmente, tem-se conhecimento que os tipos de métodos contraceptivos são: coito interrompido, métodos de barreira, métodos cirúrgicos, métodos comportamentais, dispositivo intrauterino e métodos hormonais (Santos, Rodrigues, Araújo, Vasconcelos, 2007).

A utilização dos métodos contraceptivos tem importante papel na prevenção da gravidez não planejada e na contaminação por DSTs. O conhecimento sobre os métodos contraceptivos e os riscos advindos de relações sexuais desprotegidas é fundamental para que os adolescentes possam vivenciar o sexo de maneira saudável, além de ser um direito que possibilita o exercício da sexualidade sem visar à reprodução. O enfermeiro, bem como outros profissionais de saúde, tem papel fundamental para propiciar o conhecimento adequado sobre os métodos contraceptivos, sendo as atividades de educação em saúde uma importante ferramenta para seu alcance. Assim, torna-se imprescindível saber qual o nível de conhecimento dos adolescentes sobre métodos contraceptivos e sua adesão, a fim de que se possam fundamentar as estratégias e ações preventivas e/ou assistenciais que envolvem essa temática, considerando as peculiaridades dessa fase da vida (Carvalho et al., 2012).

Segundo Schmitz, Secco, Pinheiro, e Almeida (2013), o enfermeiro é o profissional da saúde que tem grande influência na educação dos jovens e este pode esclarecer dúvidas tanto nas escolas, como em hospitais ou unidades básicas de saúde. Além disso, possui o compromisso de ajudar as pessoas na busca de soluções para as dificuldades encontradas, criando um plano de cuidados e avaliar os resultados.

Dessa forma, acredita-se que as informações acerca de planejamento reprodutivo devam ser oferecidas de maneira clara e objetiva, levando-se em consideração a compatibilidade do método indicado com o âmbito da vida afetivo-sexual da adolescente e as ambivalências reprodutivas. As informações devem englobar os efeitos colaterais, a importância da utilização correta e consistente para garantir a eficácia do método e as ações diante de alguma inconsistência que possa acontecer. Todavia, é fundamental que os profissionais busquem se certificar de que as adolescentes compreenderam a forma correta de administração, além de auxiliar na escolha de um método que mais se aproxime de suas necessidades. A contracepção deve ser um processo acompanhado de perto pelos profissionais, considerando que uma primeira abordagem com a prescrição do método e informações acerca deste não é suficiente para que as adolescentes utilizem correta e consistentemente (Silva, Nakagawa, Silva, \& Espinosa, 2019). 


\section{Conclusão}

Evidenciou-se no estudo, que o conhecimento sobre métodos contraceptivos e sexualidade, contribui para a melhor escolha da anticoncepção. O entendimento entre adolescentes e jovens é consideravelmente alto, mas, sua forma de uso e as escolhas que a levam a utiliza-las é preocupante, pois existem meios e métodos anticoncepcionais mais eficazes, proporcionando uma proteção e confiabilidade melhor. Dessa forma, destaca-se a importância do acesso a informação de qualidade em relação aos métodos contraceptivos.

Nesse sentido, observa-se que a vida sexual dos adolescentes é uma realidade incontestável, com a iniciação sexual sendo cada vez mais precoce. Por isso é imprescindível proporcionar a esse grupo uma orientação sexual envolvendo programas educativos que abranjam o contexto sócio-cultural, educacional, familiar e emocional em que os adolescentes estão inseridos, focando na questão dos métodos contraceptivos, uma vez que esse grupo necessita de informações mais concretas e sem subterfúgios acerca desse assunto. Torna-se importante a realização de estudos futuros com a finalidade de ampliar a produção científica a respeito dessa temática tão relevante, sendo de suma importância, no sentido de aprofundar discussões que possam contribuir para a promoção da saúde e na melhoria da qualidade de vida desses pacientes.

\section{Referências}

Alencar, R. D. A., Silva, L., Silva, F. A., \& Diniz, R. E. D. S. (2008). Desenvolvimento de uma proposta de educação sexual para adolescentes. Ciência \& Educação (Bauru), 14, 159-168.

Almeida, A. C., Almeida, A. C., Costa, M. R., \& Firmo, W. D. C. A. (2016). Conhecimento sobre a contracepção de emergência por adolescentes de uma escola pública de Lago Verde, Maranhão, Brasil. Revista UNINGÁ Review, 27(1).

Almeida, R. A. A. S., Corrêa, R. D. G. C. F., Rolim, I. L. T. P., Hora, J. M. D., Linard, A. G., Coutinho, N. P. S., \& Oliveira, P. D. S. (2017). Conhecimento de adolescentes relacionados às doenças sexualmente transmissíveis e gravidez. Revista Brasileira de Enfermagem, 70, $1033-1039$.

Almeida, S. K. R., de Oliveira, R. L., de Souza, L. A. C. F., Maciel, C. G., de Barros, R. R., Quaresma, N. G. S., \& do Nascimento Pacheco, C. (2021). As práticas educativas seus respectivos impactos na prevenção da gravidez na adolescência. Brazilian Journal of Health Review, 4(3), 9787-9800.

Araújo, A. K. L., \& Nery, I. S. (2018). Conhecimento sobre contracepção e fatores associados ao planejamento de gravidez na adolescência. Cogitare Enfermagem, 23(2).

Augusto, C. A., Souza, J. P. D., Dellagnelo, E. H. L., \& Cario, S. A. F. (2013). Pesquisa Qualitativa: rigor metodológico no tratamento da teoria dos custos de transação em artigos apresentados nos congressos da Sober (2007-2011). Revista de Economia e Sociologia Rural, 51 (4), $745-764$.

Bié, A. P. A., Diógenes, M. A. R., \& Moura, E. R. F. (2006). Planejamento familiar: o que os adolescentes sabem sobre este assunto? Revista Brasileira em Promoção da Saúde, 19(3), 125-130.

Botelho, L. L. R., de Almeida Cunha, C. C., \& Macedo, M. (2011). O método da revisão integrativa nos estudos organizacionais. Gestão e sociedade, 5(11), $121-136$.

Brás, M. A. M., Anes, E. M. G. J., Praça, M. I. F., \& de Fátima Morais, M. (2011). Os adolescentes e a sexualidade: assuntos da procura dos cuidados de saúde primários. International Journal of Developmental and Educational Psychology, 2(1), 413-422.

Brasil, E. G. M., Queiroz, M. V. O., \& Cunha, J. M. H. (2012). Acolhimento à adolescente na consulta de enfermagem-estudo descritivo. Online Brazilian Journal of Nursing, 11(2), 346-58.

Campos Lima Valverde, K., \& Andrade Virgínio de Oliveira, A. (2015). Adolescentes e jovens e a contracepção de emergência: Revisão integrativa da literatura. Revista de Divulgação Científica Sena Aires, 3(2), 185-194.

Carvalho, M. T. V. F., Batista, A. P. L., Figueiredo, M. F. S., Barbosa, A. A. D., Marinho, L. M., \& Caitite, L. C. (2012). Conhecimento dos adolescentes de escolas públicas de Montes Claros acerca do uso de métodos contraceptivos. Revista Renome, 1(1), 33-44.

Ercole, F. F., Melo, L. D., \& Alcoforado, C. L. G. C. (2014). Revisão integrativa versus revisão sistemática. Rev Min Enferm, 18(1), 9-12.

Ferenhof, H. A., \& Fernandes, R. F. (2016). Desmistificando a revisão de literatura como base para redação científica: método SSF. Revista ACB, 21(3), 550563.

Fiedler, M. W., Araújo, A., \& Souza, M. C. C. D. (2015). A prevenção da gravidez na adolescência na visão de adolescentes. Texto \& ContextoEnfermagem, 24, 30-37.

Freitas Rodrigues, M., \& Jardim, D. P. (2012). Conhecimento e uso da contracepção de emergência na adolescência: contribuições para a enfermagem. Cogitare Enfermagem, 17(4), 724-729.

Gurgel, M. G. I., Alves, M. D. S., Vieira, N. F. C., Pinheiro, P. N. D. C., \& Barroso, G. T. (2008). Gravidez na adolescência: tendência na produção científica de enfermagem. Escola Anna Nery, 12, 800-806. 
Kempfer, S. S., Fraga, S. M. N., da Silva Hoffman, A. C., Lazzari, D. D., \& Mafra, T. J. (2012). Contracepção na adolescência: uma questão de autocuidado. Revista de Pesquisa Cuidado é Fundamental Online, 4(3), 2702-2711.

Mendes, K. D. S., Silveira, R. C. D. C. P., \& Galvão, C. M. (2008). Revisão integrativa: método de pesquisa para a incorporação de evidências na saúde e na enfermagem. Texto \& contexto enfermagem, 17(4), 758-764.

Netto, L. D. L. Q. G., Ribeiro, B. G., \& de Azevedo Guimarães, E. A. (2011). Opção Contraceptiva de adolescentes e jovens universitários da região CentroOeste de Minas Gerais. Revista de Enfermagem do Centro-Oeste Mineiro.

Pereira, A. S., Shitsuka, D. M., Parreira, F. J., \& Shitsuka, R. (2018). Metodologia da pesquisa científica.

Pereira, J. D. C. N., Barbosa, L. U., Henriques, A. H. B., Araújo, P. M. D. O. A., Muniz, M. L. C., dos Santos Melo, E. C., \& de Figuerêdo Priori, A. R. A. (2019). Educação em saúde com adolescentes escolares acerca da sexualidade e infecções sexualmente transmissíveis: um relato de experiência. Revista Eletrônica Acervo Saúde, (29), e1130-e1130.

Queiroz, M. V. O., de Alcântara, C. M., Brasil, E. G. M., \& da Silva, R. M. (2016). Participação de adolescentes em ações educativas sobre saúde sexual e contracepção. Revista Brasileira em Promoção da Saúde, 29, 58-65.

Ribeiro, W. A., Martins, L. M., de Souza Couto, C., Cirino, H. P., Teixeira, J. M., \& de Almeida, V. L. A. (2017). Práticas educativas do enfermeiro na prevenção da gravidez na adolescência: estratégias e perspectivas. Revista Pró-UniverSUS, 8(2), 58-62.

Santana, N. C. S., de Albuquerque Chaves, P., Da Silva, L. O., Vaz, R. O., \& de Araújo, H. V. S. (2021). Contracepção reversível de longo prazo em adolescentes: benefícios e barreiras. Revista Eletrônica Acervo Enfermagem, 12, e8177-e8177.

Santos Cardoso, L. C., Bendl, A. L., dos Santos, L. T. V., de Oliveira Lima, B. L., Einloft, M., \& Souza, A. (2019). A utilização de contraceptivos hormonais por adolescentes e potenciais riscos para a saúde. Clinical \& Biomedical Research, 39(1).

Santos, A. C. F., Vador, R. M. F., Cunha, F. V., \& De Almeida, A. (2020). Abordagem do enfermeiro na gravidez na adolescência. Brazilian Journal of Health Review, 3(6), 17438-17456.

Santos, F. S., Rodrigues, O. C. F. L., de Araújo, E. C., \& de Vasconcelos, E. M. R. (2007). Opinião de adolescentes entre os 10 aos 14 anos sobre a pílula anticoncepcional e os preservativos masculino e feminino.

Schmitz, A. C., Secco, M. B., Pinheiro, T. R., \& de Almeida, A. C. C. H. (2013). Conhecimento De Adolescentes Acerca Da Contracepção De Emergência. CATUSSABA-ISSN 2237-3608, 3(1), 21-32.

Silva, M. J. P. D., Nakagawa, J. T. T., Silva, A. L. R. D., \& Espinosa, M. M. (2019). Gravidez na adolescência: uso de métodos anticonceptivos e suas descontinuidades. Revista Mineira de Enfermagem, 23, 1-7.

Soares, C. B., Hoga, L. A. K., Peduzzi, M., Sangaleti, C., Yonekura, T., \& Silva, D. R. A. D. (2014). Revisão integrativa: conceitos e métodos utilizados na enfermagem. Revista da Escola de Enfermagem da USP, 48(2), 335-345.

Sousa, L. M. M., Marques-Vieira, C. M. A., Severino, S. S. P., \& Antunes, A. V. (2017). A metodologia de revisão integrativa da literatura em enfermagem. No21 Série 2-Novembro 2017, 17.

Souza, M. T. D., Silva, M. D. D., \& Carvalho, R. D. (2010). Revisão integrativa: o que é e como fazer. Einstein 8(1), $102-106$.

Timbó, M. S. A; Silva, M. A. M; Ferreira, A. G. N; Bezerra, A. E. M; Abreu, L. D. P; Guimarães, R. X. Saúde Reprodutiva: percepção de adolescentes de um município do Estado do Ceará, Brasil.

Varela, A. C., \& Borges, A. C. Perfil e conhecimento sobre médotos anticoncepcionais de adolescentes grávidas.

Vieira, K. J., Barbosa, N. G., dos Santos Monteiro, J. C., de Almeida Dionízio, L., \& Gomes-Sponholz, F. A. (2021). Conhecimentos de adolescentes sobre métodos contraceptivos e infecções sexualmente transmissíveis. Revista Baiana de Enfermagem35, 